\title{
Assimilation of Radar Radial Velocity, Reflectivity, and Pseudo-Water Vapor for Convective-Scale NWP in a Variational Framework
}

\author{
ANWEI LAI \\ School of Atmospheric Sciences, Nanjing University of Information Science and Technology, Nanjing, and Hubei Key Laboratory for \\ Heavy Rain Monitoring and Warning Research, Institute of Heavy Rain, China Meteorological Administration, Wuhan, China, and \\ Cooperative Institute for Mesoscale Meteorological Studies, University of Oklahoma, Norman, Oklahoma \\ JidONG GAO AND STEVEn E. Koch \\ NOAA/National Severe Storms Laboratory, Norman, Oklahoma \\ Yunheng Wang, Sijie Pan, And Alexandre O. Fierro \\ Cooperative Institute for Mesoscale Meteorological Studies, University of Oklahoma, and NOAA/National \\ Severe Storms Laboratory, Norman, Oklahoma \\ Chunguang Cui \\ Hubei Key Laboratory for Heavy Rain Monitoring and Warning Research, Institute of Heavy Rain, \\ China Meteorological Administration, Wuhan, China \\ JINZHONG MIN \\ School of Atmospheric Sciences, Nanjing University of Information Science and Technology, Nanjing, China
}

(Manuscript received 26 November 2018, in final form 27 May 2019)

\begin{abstract}
To improve severe thunderstorm prediction, a novel pseudo-observation and assimilation approach involving water vapor mass mixing ratio is proposed to better initialize NWP forecasts at convection-resolving scales. The first step of the algorithm identifies areas of deep moist convection by utilizing the vertically integrated liquid water (VIL) derived from three-dimensional radar reflectivity fields. Once VIL is obtained, pseudo-water vapor observations are derived based on reflectivity thresholds within columns characterized by deep moist convection. Areas of spurious convection also are identified by the algorithm to help reduce their detrimental impact on the forecast. The third step is to assimilate the derived pseudo-water vapor observations into a convection-resolving-scale NWP model along with radar radial velocity and reflectivity fields in a 3DVAR framework during 4-h data assimilation cycles. Finally, 3-h forecasts are launched every hour during that period. The performance of this method is examined for two selected high-impact severe thunderstorm events: namely, the 24 May 2011 Oklahoma and 16 May 2017 Texas and Oklahoma tornado outbreaks. Relative to a control simulation that only assimilated radar data, the analyses and forecasts of these supercells (reflectivity patterns, tracks, and updraft helicity tracks) are qualitatively and quantitatively improved in both cases when the water vapor information is added into the analysis.
\end{abstract}

\section{Introduction}

Over the last three decades, the assimilation of radar data into convective-scale numerical weather prediction (NWP) models has been explored in a wide variety of

Corresponding author: Jidong Gao, jidong.gao@noaa.gov ways, including optimal interpolation, simple initialization technique and complex cloud analysis (Lin et al. 1993; Albers et al. 1996; Zhang et al. 1998; Zhang 1999; Ducrocq et al. 2000; Weygandt et al. 2002), three- or four-dimensional variational data assimilation (3DVAR or 4DVAR, Sun and Crook 1997, 1998; Gao et al. 1999, 2004; Fillion and Mahfouf 2000; Hu et al. 2006a, b; Xiao 
and Sun 2007; Caumont et al. 2010; Stensrud and Gao 2010; Sun and Wang 2013; H. Wang et al. 2013a,b; Wattrelot et al. 2014), the ensemble Kalman filter (EnKF, Zhang et al. 2004; Tong and Xue 2005; Aksoy et al. 2009; Yussouf and Stensrud 2010; Dowell et al. 2011), and hybrid variational and ensemble approaches (X. Wang et al. 2013; Gao and Stensrud 2014; Gao et al. 2016; Wang and Wang 2017 and citations therein). These works demonstrated that ingesting Doppler radar data information into convective-scale NWP models helped improve severe weather analyses and short-term $(\leq 6 \mathrm{~h})$ forecasts. The assimilation of radar data into convective-scale NWP, however, still bears many challenges because typical weather radars cannot directly observe the vast majority of the variables predicted by NWP models. Radar radial velocity observations contain information about one component of the wind field, whereas radar reflectivity and dual-polarization observations provide information about the distribution of various kinds of hydrometeors. None of the reflectivity and dual-polarization observations, however, are explicitly predicted by the NWP models. The functional relationships often used to diagnose radar reflectivity from the predicted hydrometeor variables are nonlinear.

Ge et al. (2013) tested the impact of assimilating measurements of different model state variables on the shortterm forecasts of supercell thunderstorm events by performing a set of observing system simulation experiments (OSSEs) using a 3DVAR cycled analysis approach. They found that among all types of measurements, horizontal wind and water vapor observations have the greatest impact on storm-scale analyses and short-range forecasts, followed by potential temperature measurements and vertical velocity. Although partial wind measurements within storms can be derived from radar data, there is far less information related to the moisture and potential temperature fields for convective-scale weather systems. More specifically, there are no direct observations/measurements of water vapor mass mixing ratio $\left(q_{v}\right)$. An algorithm using $q_{v}$ and in-cloud thermal adjustments has been employed in the Advanced Regional Prediction System (ARPS; Xue et al. 2001, 2003) complex cloud analysis scheme (Zhang 1999; Hu et al. 2006a; Schenkman et al. 2011). In this approach, the relative humidity (RH) is adjusted to $100 \%$ within cloud regions defined by a given composite radar reflectivity threshold. However, rapid forecast error growth is found in most variables with reflectivity forecasts suffering from large overestimates and positive biases (Tong 2015). The gradual insertion of water vapor mass can quickly result in overestimates of the intensity and areal coverage of convection (Fierro et al. 2016), leading to a degradation of the forecast after just a few cloud-analysis cycles (Schenkman et al. 2011; Schenkman
2012). In recent years, many other approaches aimed at assimilating $q_{v}$ retrievals from cloud and/or precipitation observations have been proposed (Macpherson et al. 1996; Jones and Macpherson 1997; Haase et al. 2000; Sokol and Rezacova 2006; Storto and Tveter 2009; Caumont et al. 2010; Wattrelot et al. 2014; Fierro et al. 2012, 2016; Carlin et al. 2017). A few recent examples are given in detail below.

Capitalizing on the importance of moisture information, Caumont et al. (2010) and Wattrelot et al. (2014) implemented a 1D + 3DVAR approach in a mesocale model developed at Meteo-France. The observed reflectivity column was used to compute the relative humidity $(\mathrm{RH})$ profile through a Bayesian inversion technique, which serves as a pseudo-observation for the subsequent 3DVAR assimilation. The application of this method in convection-allowing $(d x \leq 3$ $4 \mathrm{~km}$ ) models showed that assimilating pseudo-observed $\mathrm{RH}$ resulted in notable improvements in the short-term forecasts of accumulated precipitation (Marécal and Mahfouf 2002, 2003; Lopez and Bauer 2007; Caumont et al. 2010; Wattrelot et al. 2014). H. Wang et al. (2013a) designed a scheme to estimate in-cloud $q_{v}$ and cloud water from radar reflectivity, and assimilated these pseudo-observations into the Weather Research and Forecasting (WRF-ARW) Model. The results indicated that the assimilation of RH pseudo-observations from in-cloud $q_{v}$ adjustment had a noticeable positive impact on the short-term precipitation prediction of summer convective events. The pseudo- $q_{v}$ observations, however, were derived based on in-cloud adjustments from cloud analysis schemes (Albers et al. 1996; Zhang et al. 1998; Hu et al. 2006a), which often suffer from overpredictions of moisture-derived variables such as rainfall.

Over the past few years, Fierro et al. $(2015,2016)$ developed nudging and 3DVAR assimilation techniques for pseudo- $q_{v}$ derived from observed total lightning density fields from either the ground-based Earth Networks Total Lightning (broadband) Network (ENTLN) or the spaceborne Geostationary Lightning Mapper (GLM; Goodman et al. 2013; Fierro et al. 2019, manuscript submitted to Mon. Wea. Rev.). Over a wide range of forecast days, each of these methods revealed forecast improvements that were overall comparable to forecasts assimilating only WSR-88D data (radial velocity and/or reflectivity). Specifically, in a 3DVAR approach, it was found that assimilating lightning data alone through a simple pseudo- $q_{v}$ observation operator notably improved the short-term forecast of high-impact weather events in terms of the timing and placement of the observed convection (Fierro et al. 2016) as indicated by observed radar reflectivity fields from the three-dimensional National 
Mosaic and Multisensor Quantitative Precipitation Estimation product from National Severe Storms Laboratory (NSSL) (Zhang et al. 2011). In contrast to radar data from the U.S. NEXRAD network, lightning data do not suffer from paucity in oceanic or mountainous regions, rendering this assimilation method particularly useful for such vulnerable areas in the United States. As indicated in the first study documenting this lightning data assimilation method (Fierro et al. 2012), the direct insertion/ nudging of pseudo- $q_{v}$ observation, however, does not address the development of spurious cells in the model arising from biases and error in the initial conditions derived or downscaled from the large-scale fields of operational models [e.g., North American Mesoscale Forecast System (NAM) model]. Research is ongoing to partially mitigate this important limitation.

Carlin et al. (2017) recently proposed an alternative, attractive approach to assimilate pseudo- $q_{v}$ observations derived from dual-polarization differential reflectivity $\left(Z_{\mathrm{DR}}\right.$, Kumjian 2013; Snyder et al. 2015) fields. Their scheme first identifies $Z_{\mathrm{DR}}$ columns, as these generally are associated with locations characterized by deep moist convection (nearly undiluted updrafts). The second step of their algorithm computes pseudo- $q_{v}$ and temperature observations through a cloud analysis scheme (Hu et al. 2006a). The method was evaluated for two tornadic supercell storms and showed improvements in both the analysis and forecasts for these two cases. In particular, the analyzed updraft cores were more coherent, and the analysis contained notably fewer spurious cells compared to a control run not assimilating any dual-polarization data. The 1-h short-term forecasts exhibited a reduced northward position bias and reasonable storm propagation speeds when evaluated against observations. These forecasts, however, were based on $Z_{\mathrm{DR}}$ columns derived from only one radar site. A reliable $Z_{\mathrm{DR}}$ column algorithm from multiple radars remains to be developed in the future, which is the subject of ongoing research.

The present study is inspired by earlier research based on lightning and $Z_{\mathrm{DR}}$ data assimilation (Carlin et al. 2017; Fierro et al. 2014, 2016), with a 3DVAR approach in which both radial velocity and reflectivity are assimilated (Gao and Stensrud 2012). Similar to the $Z_{\mathrm{DR}}$ column algorithm, the Vertically Integrated Liquid water (VIL; Greene and Clark 1972) calculated from the observed reflectivity fields is used to identify the locations of deep moist convection. We use the convectivestratiform segregation method described in Zhang and Qi (2010) to identify convection regions, and to create pseudo- $q_{v}$ observations in these regions. The pseudo- $q_{v}$ observations are then assimilated into a convectionresolving NWP model along with radar radial velocity and reflectivity using a 3DVAR package (Gao and Stensrud 2012). The main goal of this study is to improve short-term $(\leq 3 \mathrm{~h})$ thunderstorm forecasts. The 3DVAR method is chosen because of its significantly lower computational burden compared to the more advanced 4DVAR, EnKF, and/or hybrid methods. As pointed out in Gao and Stensrud (2012), efficient and fast analysis methods are essential for prediction of storm-scale weather systems because of the critical need for operational centers to disseminate analyses and forecasts in a timely manner to shareholders and the public.

\section{Methodology}

\section{a. The $3 D V A R$ system}

In this study, we employed a 3DVAR data assimilation system that was initially developed at the Center for Analysis and Prediction of Storms (CAPS), and subsequently refined at NSSL. Following Gao et al. (2004), the $3 \mathrm{DVAR}$ cost function is defined as

$$
\begin{aligned}
J(\mathbf{x})= & \frac{1}{2}\left(\mathbf{x}-\mathbf{x}^{b}\right)^{\mathrm{T}} \mathbf{B}^{-1}\left(\mathbf{x}-\mathbf{x}^{b}\right) \\
& +\frac{1}{2}\left[H(\mathbf{x})-\mathbf{y}^{o}\right]^{\mathrm{T}} \mathbf{R}^{-1}\left[H(\mathbf{x})-\mathbf{y}^{o}\right]+J_{c}(\mathbf{x}),
\end{aligned}
$$

where the first term on the right-hand side defines the Euclidian distance between the analysis vector, $\mathbf{x}$, and the background, $\mathbf{x}^{b}$, weighted by the inverse of the NWP model background error covariance matrix $\mathbf{B}$. In an earlier ARPS version of this 3DVAR system (Gao et al. 2004, Hu et al. 2006a, b), the analysis vector $\mathbf{x}$ contained six variables: the three wind components $(u, v$, and $w)$, potential temperature $(\theta)$, pressure $(p)$, and water vapor mixing ratio $\left(q_{v}\right)$. Only radar radial velocity and surface observations were assimilated into this system. Hydrometeor variables were updated by a complex cloud analysis package ( $\mathrm{Hu}$ et al. 2006a). In the upgraded NSSL version (Gao and Stensrud 2012), the capability to assimilate hydrometeor-related model variables was added, which includes the mass mixing ratios for rainwater $\left(q_{r}\right)$, snow $\left(q_{s}\right)$, and hail $\left(q_{h}\right)$. The second term on the right-hand side is the observation term, which defines the (Euclidian) distance between the analysis and the observation vector, $\mathbf{y}^{o}$. In this study, $\mathbf{y}^{o}$ includes radar radial velocity, radar reflectivity, pseudo- $q_{v}$, and surface data. For radar data, the forward model $H(\mathbf{x})$ is defined in Gao and Stensrud (2012) and will be briefly discussed later; $\mathbf{R}$ represents the observation error covariance matrix, which includes both instrument and representativeness errors. The third term labeled $J_{c}(\mathbf{x})$ represents the dynamic constraints. In the original version of the ARPS 3DVAR code, the mass continuity equation 
was imposed as a weak constraint. Gao et al. $(1999,2004)$ found that this mass continuity constraint was very useful in providing accurate wind analyses, especially for vertical velocity. More recently, a modified mass constraint based on the WRF model equations was included in this 3DVAR scheme. The cost function [Eq. (1)] was converted into an incremental form by defining a new control variable involving the square root of the background error covariance matrix B (Gao et al. 2004), which is modeled by a recursive filter (Purser et al. 2003a, b).

The radar forward observation operator for radial velocity, which includes the effects of Earth's curvature is written as follows,

$$
v_{r}=\frac{d h}{d r} w+\frac{d s}{d r}(u \sin \phi+v \cos \phi),
$$

where $v_{r}$ is the projected radial velocity, $r$ is the slant range (ray path distance), $h$ is the height above the curving Earth's surface, $s$ is the distance along Earth's surface, and $\phi$ is the radar azimuth angle. The propagation of the beams is assumed to follow the 4/3effective Earth radius model (Doviak and Zrnić 1993; Gao et al. 2008).

The forward operator for the equivalent radar reflectivity factor in linear units $\left(\mathrm{mm}^{6} \mathrm{~m}^{-3}\right)$ is obtained by summing the contributions from three mass mixing ratios-namely, rain, snow, and hail-using the following formulation (Lin et al. 1983; Gilmore et al. 2004; Dowell et al. 2011):

$$
Z_{e}=Z\left(q_{r}\right)+Z\left(q_{s}\right)+Z\left(q_{h}\right) .
$$

Details behind each of these terms can be found in Tong and Xue (2005) and Dowell et al. (2011). All the forecast experiments employ the Thompson microphysics, which predicts the number concentration for ice and rainwater (instead of assuming a constant value $N_{0}$ ) and the mass mixing ratio of five hydrometeor species (cloud, ice, rain, snow, hail).

Given that the reflectivity factor is a function of three hydrometeor variables [Eq. (3)], the assimilation of reflectivity observations becomes an even more underdetermined problem. For example, it is possible to obtain a nonzero rainwater mixing ratio in the upper levels of the model where only snow and graupel mixing ratios are expected. To alleviate this potential limitation, a forward reflectivity operator utilizing information from the model background has been proposed (Gao and Stensrud 2012):

$$
Z_{e}=\left\{\begin{array}{ll}
Z\left(q_{r}\right)+Z\left(q_{h}\right) & T_{b}>5^{\circ} \mathrm{C} \\
Z\left(q_{s}\right)+Z\left(q_{h}\right) & T_{b}<-5^{\circ} \mathrm{C} \\
\alpha Z\left(q_{r}\right)+(1-\alpha)\left[Z\left(q_{s}\right)+Z\left(q_{h}\right)\right] & -5^{\circ}<T_{b}<5^{\circ} \mathrm{C}
\end{array},\right.
$$

where $\alpha$ varies linearly between 0 at $T_{b}=-5^{\circ} \mathrm{C}$ and 1 at $T_{b}=5^{\circ} \mathrm{C}$, and $T_{b}$ is the background temperature from a NWP model. Gao and Stensrud (2012) found that the modified equation in Eq. (4) was more accurate and effective in obtaining realistic hydrometeor profiles when the reflectivity data were assimilated.

Multiple analysis passes are used to analyze different observation types with different filter scales in order to consider the variations in the observation spacing among different observation data. Xie et al. (2011) and $\mathrm{Li}$ et al. (2010) proved theoretically that the multiplepass approach with a recursive filter is superior to the conventional single-pass 3DVAR method. In this study, three passes of the recursive filter are used. The first pass used a horizontal decorrelation length scale $L=24 \mathrm{~km}$, the second pass $L=12 \mathrm{~km}$, and the third pass $L=4 \mathrm{~km}$. The pseudo- $q_{v}$ observations are only assimilated in the third pass.

\section{b. Pseudo-water vapor mixing ratio observations derived from VIL}

As discussed previously, among all types of measurements, water vapor observations have one of the greatest impacts on storm analyses and short-range forecasts (Fierro et al. 2012, Ge et al. 2013). To improve the short-term $(0-3 \mathrm{~h})$ forecast of high-impact weather events at convection-resolving scales, a new method is proposed to derive pseudo- $q_{v}$ observations based on VIL. One key aspect of this method is to use the VIL derived from reflectivity observations to identify areas of deep moist convection (Zhang and Qi, 2010), as described herein.

As a first step, the radar reflectivity data from multiple WSR-88Ds within the forecast domain are blended and interpolated onto the model grid after being subjected to a basic quality control (e.g., removing radar clutter and nonmeteorological reflectivity) to yield a threedimensional gridded reflectivity data mosaic. If reflectivity data from multiple radars exist at the same grid point, the largest value is chosen. The quality control (e.g., de-aliasing radial velocity) and processing of the Doppler radar data are the same as in Gao et al. (2013).

The procedure for creating the pseudo- $q_{v}$ observations is highlighted in Fig. 1. First, the VILs (a fixed constant $N_{0}=8 \times 10^{6} \mathrm{~m}^{-4}$ is assumed) are calculated from the $3 \mathrm{D}$ gridded observed reflectivity data mosaicked from multiple radars (Greene and Clark 1972; Zhang and Qi 2010) (referred to as "observed VIL") and the background reflectivity produced by WRF using Eq. (4) (referred to as "background VIL"), respectively. The convective-stratiform segregation method of Zhang and Qi (2010) is employed to segregate the convective and stratiform columns. Using VIL to differentiate 


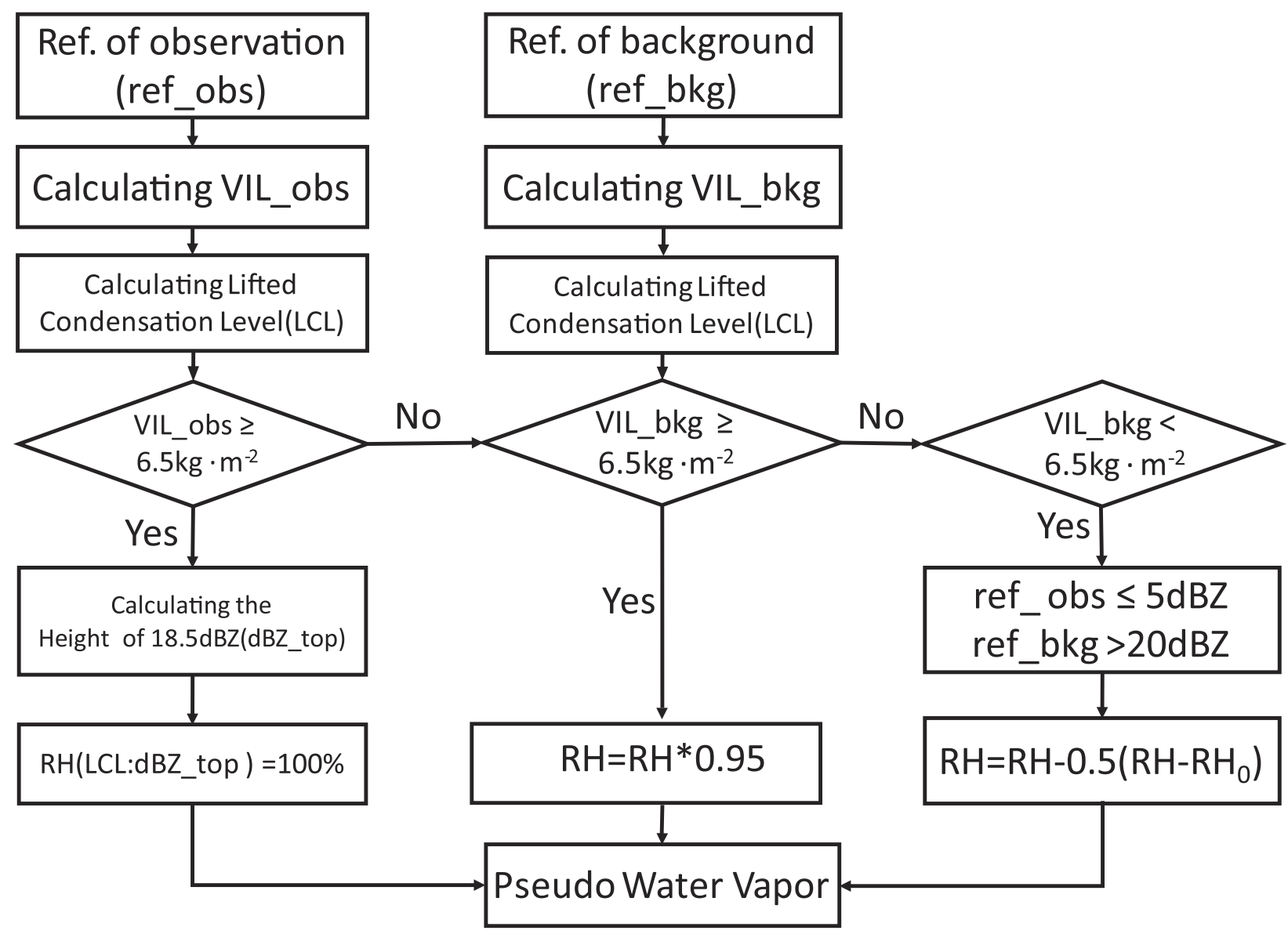

FIG. 1. Flowchart highlighting the steps for deriving pseudo-water vapor mixing ratio. "Ref"' stands for reflectivity; the VIL_obs and VIL_bkg represent the vertically integrated liquid water calculated from the observed reflectivity and simulated reflectivity of the background field, respectively. $\mathrm{RH}_{0}$ is the threshold of relative humidity whose value is dependent on height.

between convective and stratiform regions was shown to be, overall, more reliable than using the reflectivity thresholds. It is because the later has difficulty distinguishing some regions of the trailing stratiform precipitation from regions of convective precipitation (Zhang and Qi 2010).

If the VIL of a given model grid column exceeds a fixed threshold (set here to a default of $6.5 \mathrm{~kg} \mathrm{~m}^{-2}$ ) in both the observed and model background reflectivity, the column is classified as "convective" and stratiform otherwise. As indicated in Zhang and Qi (2010), the VIL threshold is empirical, and based on subjective analyses of composite reflectivity from several squall-line events in the central United States during 2008 and 2009. The $\mathrm{RH}$ in the identified convective columns is set to $100 \%$ between the lifted condensation level (LCL) and a fixed "cloud top" height defined by a fixed threshold of $18.5 \mathrm{dBZ}$ (Klazura and Imy, 1993), which is similar to Fierro et al. (2016, 2019, manuscript submitted to Mon. Wea. Rev.).
Often, however, background fields may contain spurious convection where the observed reflectivity indicates stratiform columns or "no-rain" echoes, especially when invoking high-frequency radar DA cycles. To alleviate this drawback, two scenarios are considered. If the observed VIL is less than the threshold value of $6.5 \mathrm{~kg} \mathrm{~m}^{-2}$, but the background VIL exceeds this threshold, then spurious convection is identified. In this case, the RH from the model background is decreased to $95 \%$ of its initial value above the LCL. If (i) both the observed and background VIL are smaller than the threshold, (ii) the observed reflectivity is less than $5 \mathrm{dBZ}$, and (iii) the background reflectivity is greater than $20 \mathrm{~dB} Z$ for a given grid, then this grid column is classified as a "no-rain" region (Gao et al. 2018). For these no-rain areas, the model background $\mathrm{RH}$ is reduced by half of the difference between the background $\mathrm{RH}$ and a reference $\mathrm{RH}_{0}$, which is similar to the value used to calculate the volumetric cloud fraction in the cloud analysis developed by Zhang (1999), namely, $\mathrm{RH}_{0}=95 \%$ for height ( $z$, AGL) 


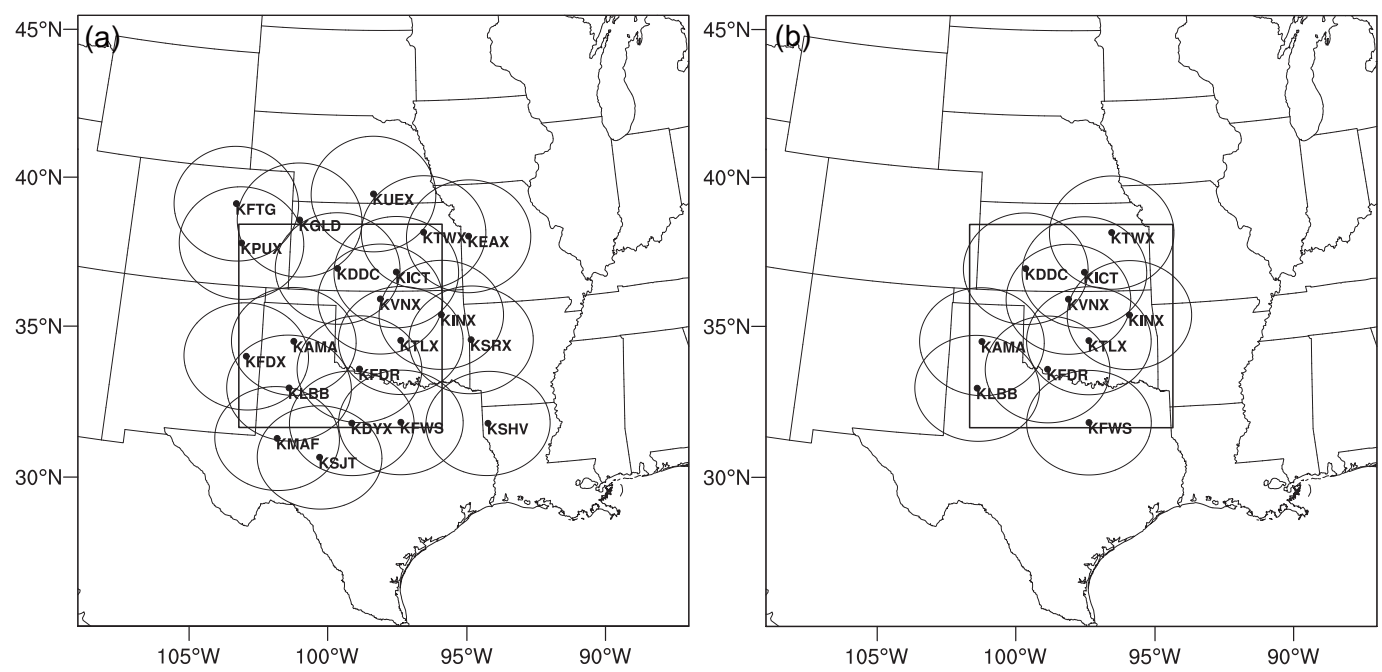

FIG. 2. Simulation domains (black square) and locations of the radar sites for (a) 16 May 2017 and (b) 24 May 2011. The maximum range of each radar is shown by a gray circle. The first case utilizes 21 radars and the second case has just 10 radars.

below $600 \mathrm{~m}, 90 \%$ between $z=600-1500 \mathrm{~m}, 85 \%$ between $z=1500$ and $2500 \mathrm{~m}$, and $75 \%$ for $z \geq 2500 \mathrm{~m}$. The purpose for this approach is to hamper spurious cell development in the domain (Fig. 1). Out of the above two scenario, the RH from model background are not changed due to the uncertainty of the relationship between RH and reflectivity.

It is relevant to mention that the derivation of the pseudo$q_{v}$ observations from the $\mathrm{RH}$ profiles herein contains three main sources of uncertainties. The first is the identification/ classification of the "deep moist convection" areas, which depends on the VIL threshold value and the radar observational horizontal and vertical coverage regions. The second is the calculation of saturation water vapor mixing ratio, whose accuracy depends on the quality of pressure and temperatures in the background field. The third is the empirical variable related to relative humidity adjustment. To reduce these uncertainties, the pseudo-observation error can be set a relatively large value. In our experiments, $3.0 \mathrm{~g} \mathrm{~kg}^{-1}$ is used, similar to Fierro et al. (2016).

\section{Experimental design}

To determine the impact of the assimilation of pseudo- $q_{v}$ observations by the 3DVAR method on short-term convective NWP, two tornado supercell events were selected: 16 May 2017 over the boundary of western Oklahoma and the Texas Panhandle (Case 1, Fig. 2a) and the 24 May 2011 tornado outbreak in central Oklahoma (Case 2, Fig. 2b).

The forecast model used in this study is the threedimensional compressible nonhydrostatic WRF Model (version 3.7.1) with Advanced Research WRF dynamic solver (WRF-ARW; Skamarock et al. 2008), which has been used for a wide range of applications across scales ranging from meters to thousands of kilometers. The model physics configuration includes the Thompson microphysics scheme (Thompson et al. 2008), the Yonsei University planetary boundary layer scheme, the Dudhia shortwave radiation scheme (Dudhia 1989), and the Rapid Radiative Transfer Model (RRTM) longwave radiation scheme (Mlawer et al. 1997). No cumulus parameterization scheme was employed. In this study, the model domain size for both cases was set to $750 \mathrm{~km} \times$ $750 \mathrm{~km}$, with a horizontal grid spacing of $1.5 \mathrm{~km}$. The geographical center of the model domain for the first case is at $\left(35.84^{\circ} \mathrm{N}, 99.75^{\circ} \mathrm{W}\right)$ and the second at $\left(35.84^{\circ} \mathrm{N}\right.$, $\left.98.00^{\circ} \mathrm{W}\right)$. The stretched vertical grid consists of 51 levels with a top set at $50 \mathrm{hPa}(\sim 20-22 \mathrm{~km} \mathrm{SL})$. The time step for the integration of the prognostic equations was set to $6 \mathrm{~s}$.

The flowchart of the cycled data assimilation system and forecast for the two case studies selected is shown in Fig. 3. The model is cold started at 1900 UTC, and the data assimilation is cycled at $15 \mathrm{~min}$ intervals until 2300 UTC. During the 4-h cycling period herein (Fig. 3), 3-h forecasts are launched every hour. For Case 1, the 3-km High-Resolution Rapid Refresh (HRRR) forecast fields initialized at 1800 UTC 16 May 2017 are interpolated into the analysis and forecast domain (Fig. 2) to provide initial background fields for the data assimilation cycles and boundary conditions for short-term forecasts. Given that the HRRR fields were not yet available for Case 2, the analysis fields of the Global Forecast System (GFS-ANL, $0.5^{\circ}$ ) from 1800 UTC 24 May to 0300 UTC 25 May 2011 at 3-h interval are used instead. 


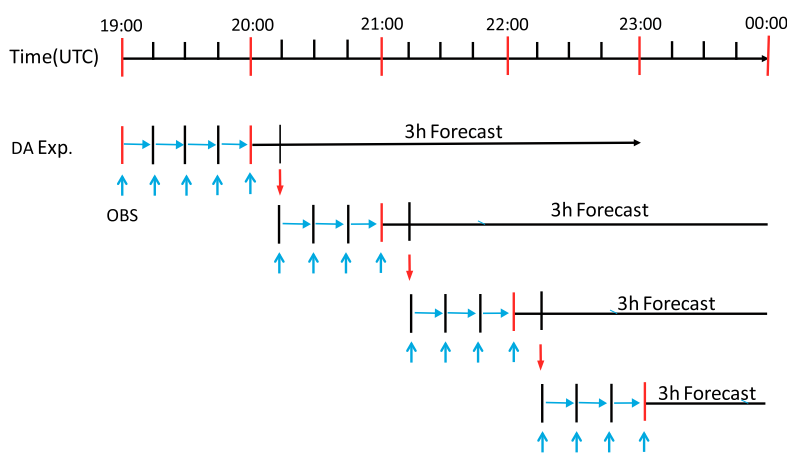

FIG. 3. Illustration of data assimilation cycles and forecast cycles used for both case studies. "OBS" represents the assimilated observations, such as radar velocity and reflectivity, surface data, and the pseudo-water vapor. The observations are assimilated every 15 min, with a 3-h forecast launched every hour. The blue arrows indicate the time at which the observations are assimilated, and the red lines indicate the time at which the 3 -h forecasts are launched.

The assimilation of radar data in this study includes the radial velocity, reflectivity and pseudo- $q_{v}$ observations derived from the NEXRAD Level-II data obtained from the National Centers for Environmental Information repository (https://www.ncdc.noaa.gov/nexradinv/). For Case 1 (2), data from 21 (10) radars overlapped the simulation domain, respectively (Fig. 2). Four experiments were performed: The control runs, labeled as C1Rad and C2Rad for each case, respectively, assimilated radar data and surface observations from the Oklahoma Mesonet. Experiments C1RadPQ and C2RadPQ were the same as control but added the assimilation of pseudo- $q_{v}$ observations. A summary of the details behind each experiment is provided in Table 1.

\section{Results}

\section{a. 16 May 2017 case}

On 16 May 2017, environmental conditions favored the development of severe thunderstorms across the eastern Texas and Oklahoma Panhandles. Early in the afternoon, the first convective cells initiated off a dryline near Hutchinson to Hansford, Texas, and gradually moved northeastward, eventually reaching Beaver County, Oklahoma (Fig. 4a). These storms produced at least two weak tornadoes and baseball size hail north of Beaver County. More thunderstorms initiated farther south near the dryline in eastern Carson and Armstrong County, Texas. These storms produced very large hail (up to tennis ball size) and a few tornadoes as they gradually moved eastward, toward Wheeler, Texas. One supercell moved into Collingsworth County, and then produced a weak tornado just west of the Texas and Oklahoma state line 10 miles east of Collingsworth,
TABLE 1. List of experiments.

\begin{tabular}{lllc}
\hline \hline & Experiments & Observation & $\begin{array}{c}\text { Pseudo- } \\
\text { observation }\end{array}$ \\
\hline 16 May 2017 & C1Rad & Radar + mesonet & - \\
& C1RadPQ & Radar + mesonet & $q_{v}$ \\
24 May 2011 & C2Rad & Radar + mesonet & - \\
& C2RadPQ & Radar + mesonet & $q_{v}$ \\
\hline
\end{tabular}

Texas. This storm then weakened somewhat, only to regain strength to eventually produce the Elk City, Beckham, Oklahoma, tornado around 0035 UTC, which resulted in one fatality. In total, seven tornadoes together with several large hail events were reported in Oklahoma alone (refers to the storm report, https:// www.spc.noaa.gov/climo/reports/170516_rpts.html).

The impact of assimilating VIL-based pseudo- $q_{v}$ observations in conjunction with radar radial velocity and reflectivity is evaluated first. The analysis increments of $q_{v}$, and an overlay comparing the observed reflectivity to the background reflectivity exceeding $35 \mathrm{~dB} Z$ following the assimilation of pseudo- $q_{v}$ observations at $3 \mathrm{~km}$ above ground level (AGL), is shown in Fig. 4 for the analysis times 1900, 2100, and 2300 UTC. It can be seen that, at 1900 UTC, there are two weak $q_{v}$ increment areas over the north Texas panhandle with a maximum value of $\sim 0.9 \mathrm{~g} \mathrm{~kg}^{-1}$ (Fig. 4a). The observed reflectivity echoes and model forecasted background echoes are displaced by about $25-50 \mathrm{~km}$ from each other (Fig. 4b). During each successive data assimilation cycle, the convective cells over the north Texas Panhandle gradually move northeastward into the Oklahoma Panhandle and, later, over southwest Kansas where multiple supercell mergers (upscale growth) resulted in the formation of a mesoscale convective system (MCS) at 2300 UTC. At 2100 UTC, most of the simulated storms are closely collocated with the observed storms though slight displacement errors between the observation and background still exist (Fig. 4d). The $q_{v}$ increments are primarily seen where large $(>35 \mathrm{dBZ})$ radar echoes exist in the observations but with a smaller areal coverage because of the small decorrelation length scale ( $L=4 \mathrm{~km}$ ) chosen (Fig. $4 \mathrm{c}$ ). In areas where spurious echoes were identified by the algorithm, the $q_{v}$ increments are negative, whose primary effect is to gradually weaken some of the spurious cells in the analysis. At 2300 UTC, the three analyzed supercell storms located at the boundary between Texas and Oklahoma developed more rapidly than observed. Similar to 1900 and 2100 UTC, the positive $q_{v}$ increment areas are mainly collocated within strong radar echo regions, while the negative $q_{v}$ increment areas are collocated with spurious echoes in the analysis domain. The maximum (minimum) 

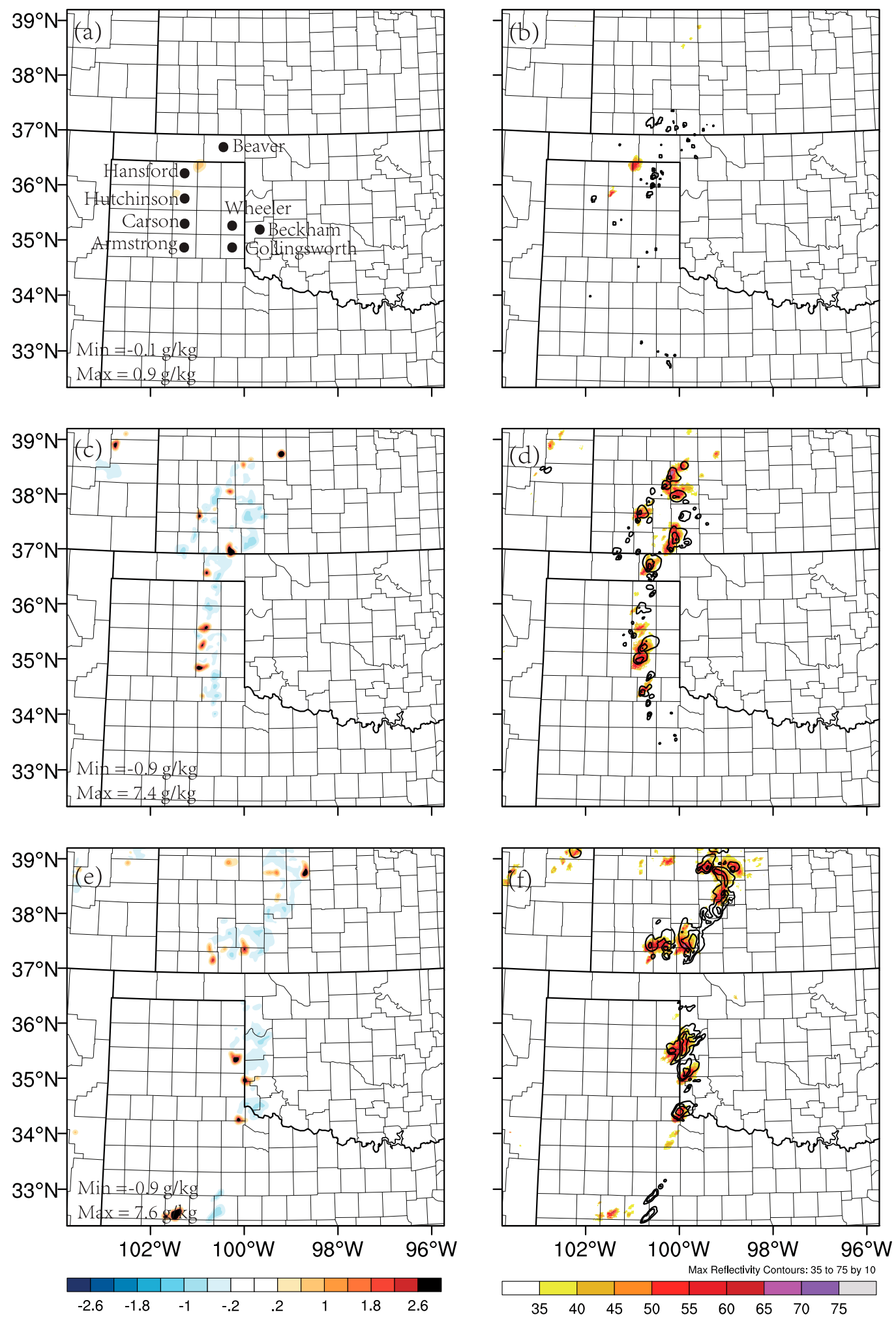

FIG. 4. (left) Analysis increments for $q_{v}$ at $3 \mathrm{~km}$ AGL, and (right) observed and model background reflectivity fields exceeding $35 \mathrm{~dB} Z$ (shaded for observed reflectivity at 5-dBZ interval and black contour for background reflectivity in 10-dBZ interval) for C1RadPQ at (a),(b) 1900 UTC, (c),(d) 2100 UTC, and (e),(f) 2300 UTC 16 May 2017. The respective county names are labeled in (a). 
value of the $q_{v}$ increment was $7.6(-0.9) \mathrm{g} \mathrm{kg}^{-1}$, respectively. At this time (2300 UTC), the number of spurious storm cells is notably reduced compared to earlier times (1900 and 2100 UTC).

The analyzed reflectivity fields at 2300 UTC for C1Rad (Fig. 5b) and C1RadPQ (Fig. 5c) show that the assimilation of pseudo- $q_{v}$ produces three well-defined supercell objects near the Texas and Oklahoma border when compared against observed composite reflectivity fields in term of storm locations and storm intensity (Fig. 5a). The southernmost supercell near the Texas and Oklahoma border for C1RadPQ is more vigorous in comparison with $\mathrm{C} 1 \mathrm{Rad}$, and is more consistent with the observations. From the observed composite reflectivity fields (Figs. 5a,d,g,j), there are several MCSs propagating east-northeastward. To better analyze and discriminate the comparisons, we divide the precipitation system into three main regions from north to south (labeled $\mathrm{A}, \mathrm{B}$, and $\mathrm{C}$ ) within the simulation domain (Fig. 5a). At the analysis time (2300 UTC), a weak convective cell is seen in region $\mathrm{C}$. A few hours later, this cell matures further with new cells continuously developing/back building from the southern boundary of the domain (Figs. 5g,j). A cluster of several storm cells is seen in region $\mathrm{A}$, which gradually drifts northeastward and, ultimately, outside of the simulation domain by 0300 UTC. The northernmost and middle storms are stronger than the ones to the south. At 0000 UTC, the northernmost cell splits into several smaller ones, resulting in the formation of two additional mature supercells (Figs. 5d,g). At 0200 UTC, the cells in region B gradually weaken while moving northeastward. During the same period, several new cells grow at/near the boundary of the simulation domain (Fig. $5 \mathrm{j}$ ).

At 1-h forecast valid at 0000 UTC, the southernmost cell in region $\mathrm{B}$ vanishes in $\mathrm{C} 1 \mathrm{Rad}$ (Fig. 5e); but intensifies in C1RadPQ (Fig. 5f), in better agreement with the observations (Fig. 5d). At 1.5-h forecast (valid at 0030 UTC), the middle supercell near Elk City, Oklahoma, in region B for C1RadPQ intensified quickly (Fig. 5i), which is also more consistent with the observations indicating the presence of an EF3 tornado there at $\sim 0030$ UTC. Although the same supercell is also well predicted at 1-h forecast (valid at $0000 \mathrm{UTC}$ ) in C1Rad (Fig. 5e), this storm weakened very quickly until completely disappearing by 3-h forecast (Fig. 5k).

The above focuses on only one $0-3-h$ forecast realization. To provide a more thorough examination of the impact of the pseudo- $q_{v}$ assimilation, the simulated composite reflectivity swaths and $2-5-\mathrm{km}$ updraft helicity (UH) tracks initiated at four different times are overlaid with the SPC severe storm reports (tornadoes, hail, and damaging wind) in Figs. 6 and 7 . The reflectivity swaths and UH tracks are based on four 0-3-h model forecast output every $15 \mathrm{~min}$. For the forecast initialized at 2000 UTC, the impact of the pseudo- $q_{v}$ is limited. The predicted composite reflectivity tracks are similar in both experiments (Figs. 6b,c) with both exhibiting notable discrepancies relative to the observed reflectivity tracks and the SPC reports (Fig. 6a). But for the forecast initialized at 2100 UTC, the assimilation of pseudo- $q_{v}$ has a more noticeable positive impact as indicated by forecast reflectivity tracks becoming gradually more consistent with the observations (Fig. 6d), especially near the Oklahoma and Texas Panhandle border (Fig. 6f vs Fig. 6e). The forecast tracks of two main supercells near the center of the domain improved when the forecast is initialized at 2200 UTC as evidenced by severe weather reports becoming better aligned with the main simulated storms in C1RadPQ (Fig. 6i). In contrast, the C1Rad exhibits a clear northward bias for all three major storm tracks over the Oklahoma and Texas Panhandle border (Fig. 6h). For the forecast initialized at 2300 UTC, the tracks for all three major storms are well forecast with very small phase errors in west Oklahoma for C1RadPQ (Fig. 61). Only two storm tracks are correctly predicted in C1Rad. For the MCS in southwest Kansas, the embedded supercells which produced tornadoes and severe hail reports near the north central portion of the domain appear to be reasonably well predicted in both experiments. Also, both experiments miss the storms associated with the hail reports in the western part of the domain and exhibit a southward bias relative to the tornadoproducing convection. Additionally, the two supercells located near the southern boundary of the domain produce weaker-than-observed reflectivity tracks. To properly account for these supercells in our forecast experiments, a larger simulation domain would have likely been needed.

As evidenced by the $2-5-\mathrm{km}$ UH tracks initiated at four different forecast times $(2000,2100,2200$, and 2300 UTC), the predicted rotational tracks gradually become more consistent with the SPC storm reports; especially when the pseudo- $q_{v}$ observations are assimilated (Fig. 7). The UH tracks are narrower than the maximum reflectivity tracks. These comparisons thus demonstrate more directly the positive impact of cycled pseudo- $q_{v}$ assimilation.

To evaluate the impact of assimilating pseudo- $q_{v}$ more quantitatively, equitable threat scores [ETS; Eqs. (1) and (2) in Clark et al. (2010)] are calculated for 0-3-h forecasts initialized at four different times in both C1Rad and C1RadPQ (Fig. 8). A perfect analysis or forecast is defined as ETS $=1.0$, and a poor analysis and forecast are associated with ETS values close to 0 . These values are calculated for the composite reflectivity 

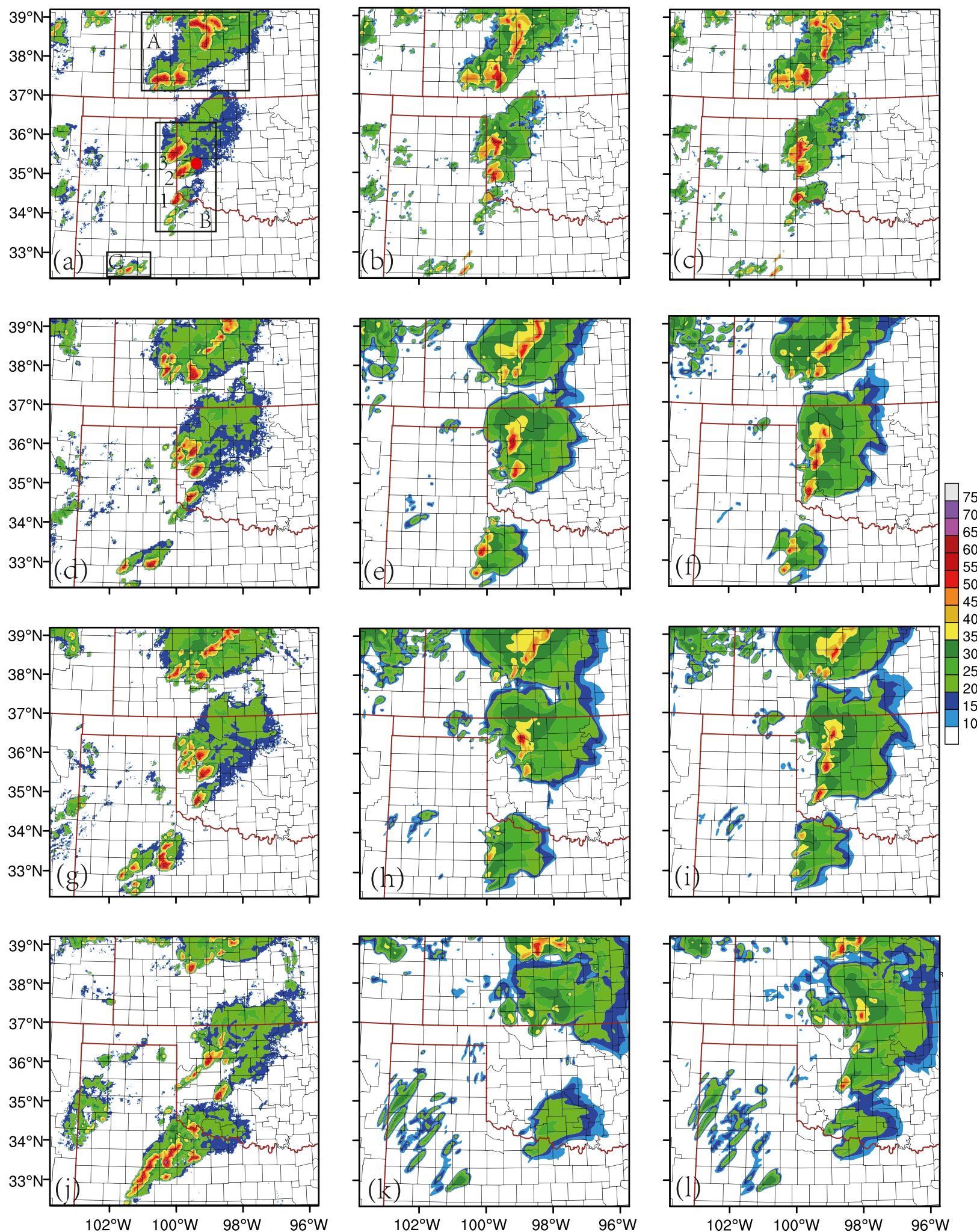

FIG. 5. (left) Horizontal cross sections of observed composite reflectivity, and corresponding analyses and forecasts from (middle) C1Rad and (right) C1RadPQ for 0-3-h forecasts beginning at 2300 UTC 16 May 2017. Plots are shown for the initial time at (a)-(c) 2300 UTC, 1-h forecast valid at (d)-(f) 0000 UTC, 1.5-h forecast valid at (g)-(i) 0030 UTC, and 3-h forecast valid at (j)-(l) 0200 UTC. The red filled circle in (a) marks the location of Elk City. 

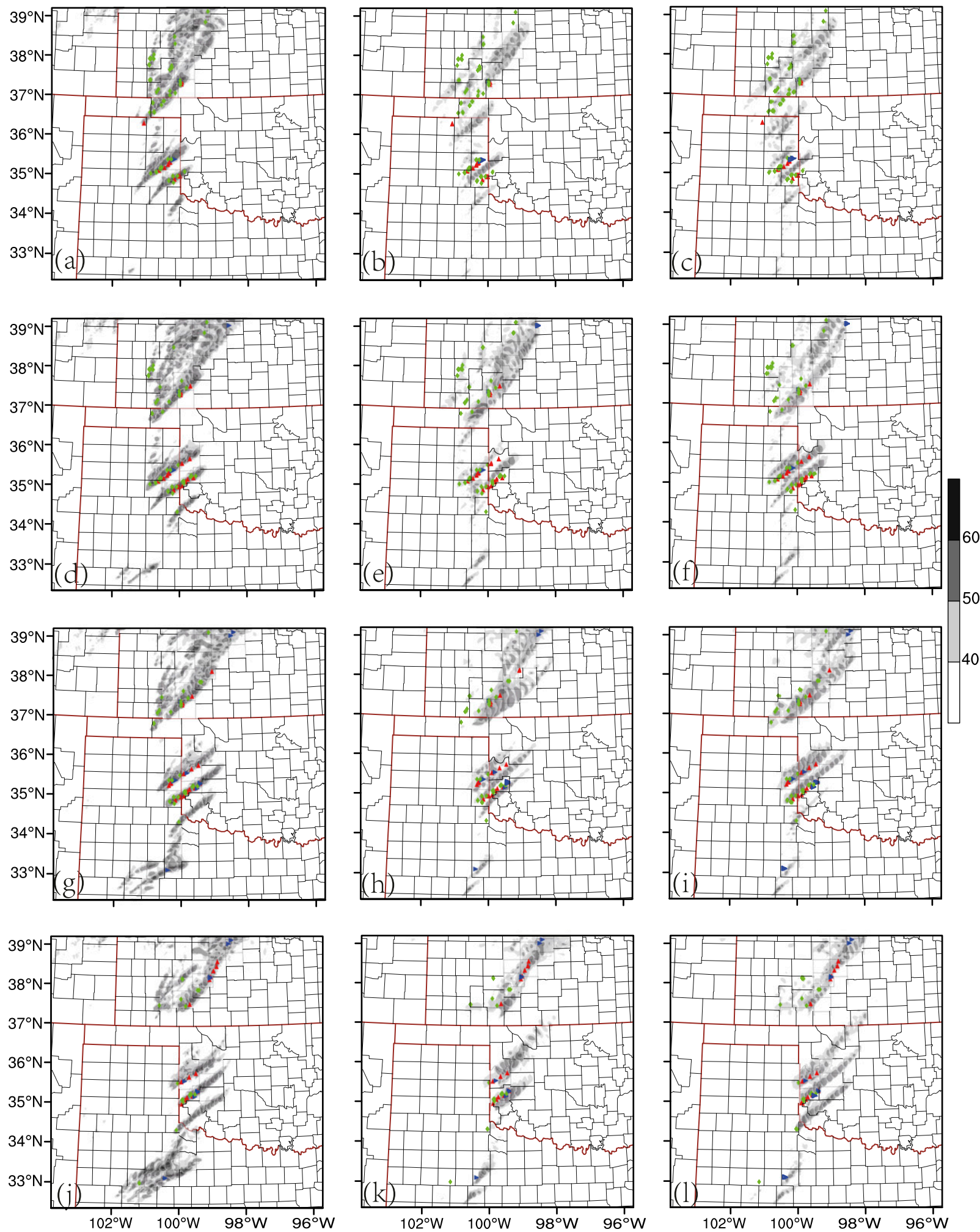

FIG. 6. Composite maximum reflectivity swaths: (left) observed, (middle) C1Rad, and (right) C1RadPQ for 0-3-h forecasts beginning at (a)-(c) 2000 UTC, (d)-(f) 2100 UTC, (g)-(i) 2200 UTC, and (j)-(l) 2300 UTC 16 May 2017. The red triangles, green rhombuses, and blue triangles represent the observed tornadoes, hail, and damaging wind events, respectively. 

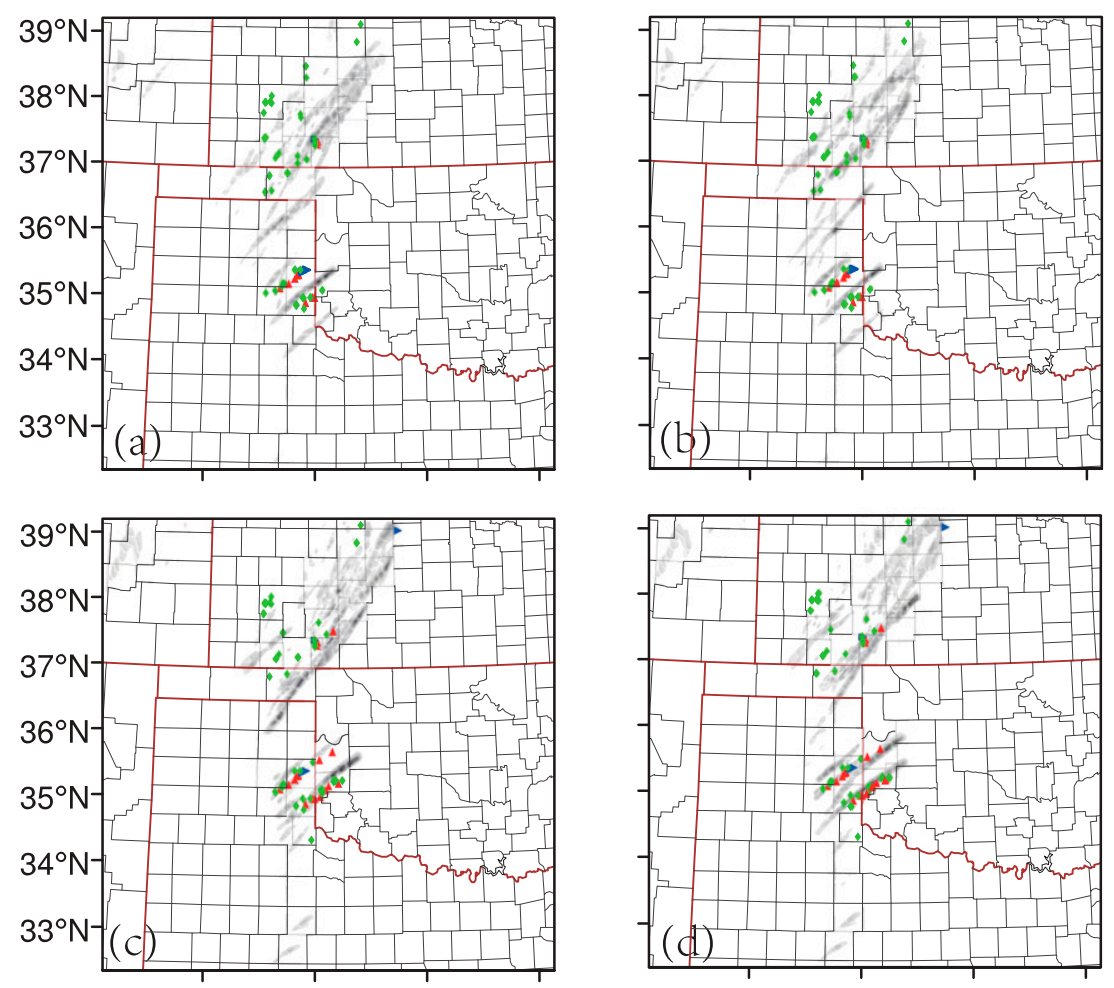

275

225

175
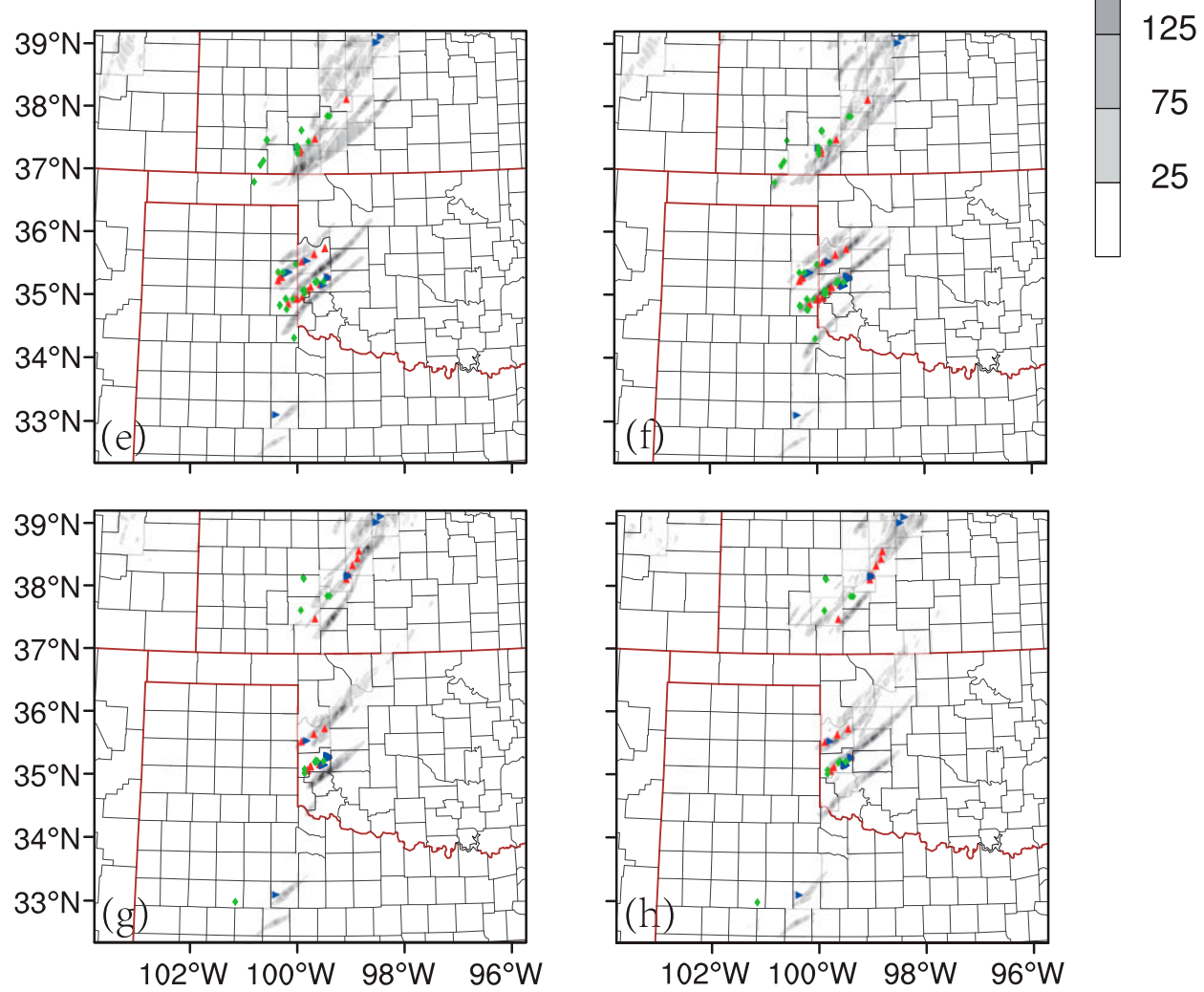

FIG. 7. As in Fig. 6, but for 2-5-km updraft helicity tracks $\geq 25 \mathrm{~m}^{2} \mathrm{~s}^{-2}$ (gray shading) at each grid point. 
thresholds of 20,30, and $40 \mathrm{dBZ}$. The ETS for C1RadPQ remains superior for the entire $0-3$-h forecast duration compared with that of $\mathrm{C} 1 \mathrm{Rad}$, indicating an overall positive impact of the pseudo- $q_{v}$ assimilation. To provide a more complete view of the overall performance of the forecasts valid at different times, performance diagrams (Roebber 2009), which conveniently merge the probability of detection (POD), critical success index (CSI), success ratio-one minus false alarm ratio (FAR), and frequency bias are analyzed. Diagrams of the $0-3$ forecasts initialized at different times show that, for most forecasts, C1RadPQ produces higher CSI and POD for reflectivity at all thresholds (i.e., 20, 30, and $40 \mathrm{dBZ}$ ), along with an increase in success ratio. When the reflectivity threshold is increased from 20 to $40 \mathrm{~dB} Z$, biases for all forecasts show a reasonable increase for both DA experiments. These diagrams illustrate further the benefit of assimilating pseudo- $q_{v}$ observations, especially for forecasts initialized at later times (Figs. 9j,k,1).

\section{b. 24 May 2011 case}

On 24 May 2011, a significant tornado outbreak of long-lived supercell thunderstorms occurred in central and northern Oklahoma, north Texas, and west Kansas (Fierro et al. 2012). By the end of the day, a total of 12 tornadoes including two EF-3, two EF-4, and one EF-5 tornadoes were reported in Oklahoma alone. These tornadoes knocked down power poles, trees, damaged buildings, and resulted in 11 fatalities and nearly 300 injuries. Early on 24 May 2011, a strong upper-level trough moved eastward over the Rocky Mountains. Ahead of the trough, a low-level jet from the south brought moist, warm air into western Oklahoma, east of a well-defined dryline where a saturated layer extended up to $850 \mathrm{hPa}$. Surface-based, most unstable, convective available potential energy values were estimated to reach $2500-4000 \mathrm{~J} \mathrm{~kg}^{-1}$ (Tanamachi et al. 2015). In west central Oklahoma, thunderstorms developed in the early afternoon, and quickly intensified into supercells as they gradually moved northeastward (Fierro et al. 2012). These supercells lasted for several hours and produced long-tracked tornadoes and large hail. The timing of the tornadoes near the Oklahoma City metro area came during the rush hour rendering this outbreak particularly dangerous.

Similar to the first case, the analysis results are first evaluated from a 4-h data assimilation period using 15-min assimilation frequency. The analysis increment of $q_{v}$, the observed reflectivity, and background reflectivity exceeding $35 \mathrm{dBZ}$ following the assimilation of pseudo- $q_{v}$ observations at $3 \mathrm{~km}$ AGL at the analysis time 1900, 2100, and 2300 UTC are shown in Fig. 10. At the beginning of
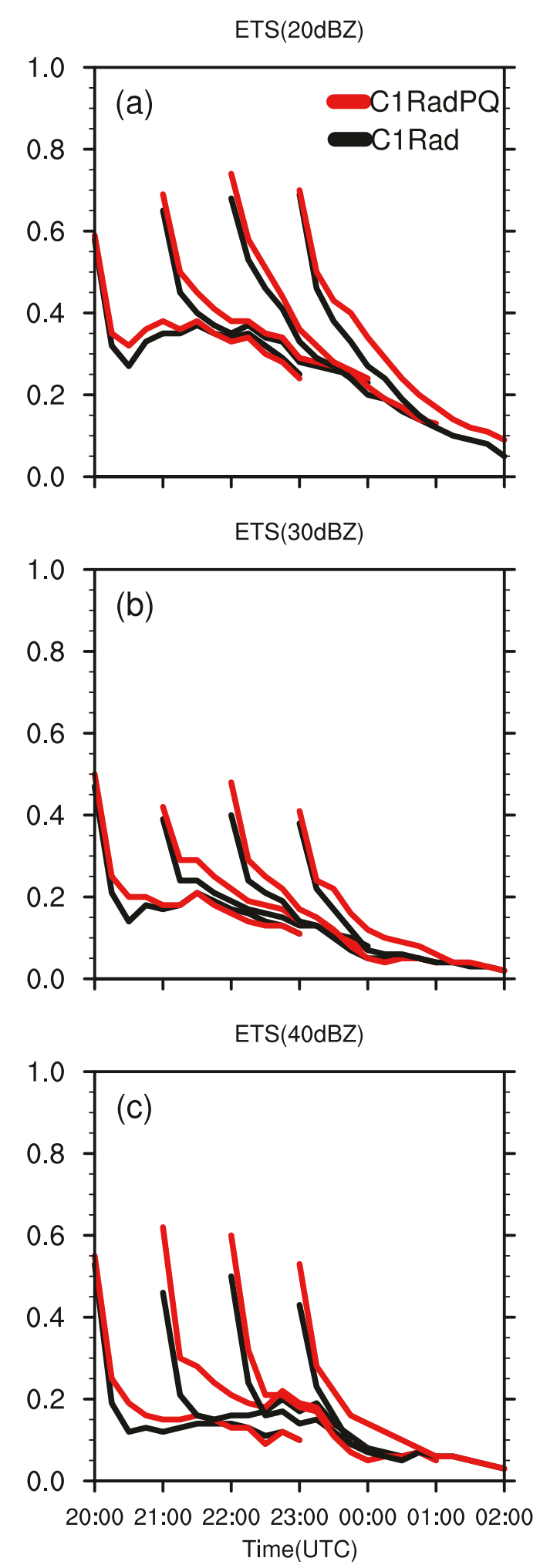

FIG. 8. Equitable threat score (ETS) of each of the $0-3$-h forecast for reflectivity thresholds of (a) 20-, (b) 30-, and (c) 40-dBZ thresholds for 16 May 2017. Black lines for the C1Rad forecasts and red lines for the C1RadPQ forecasts. 

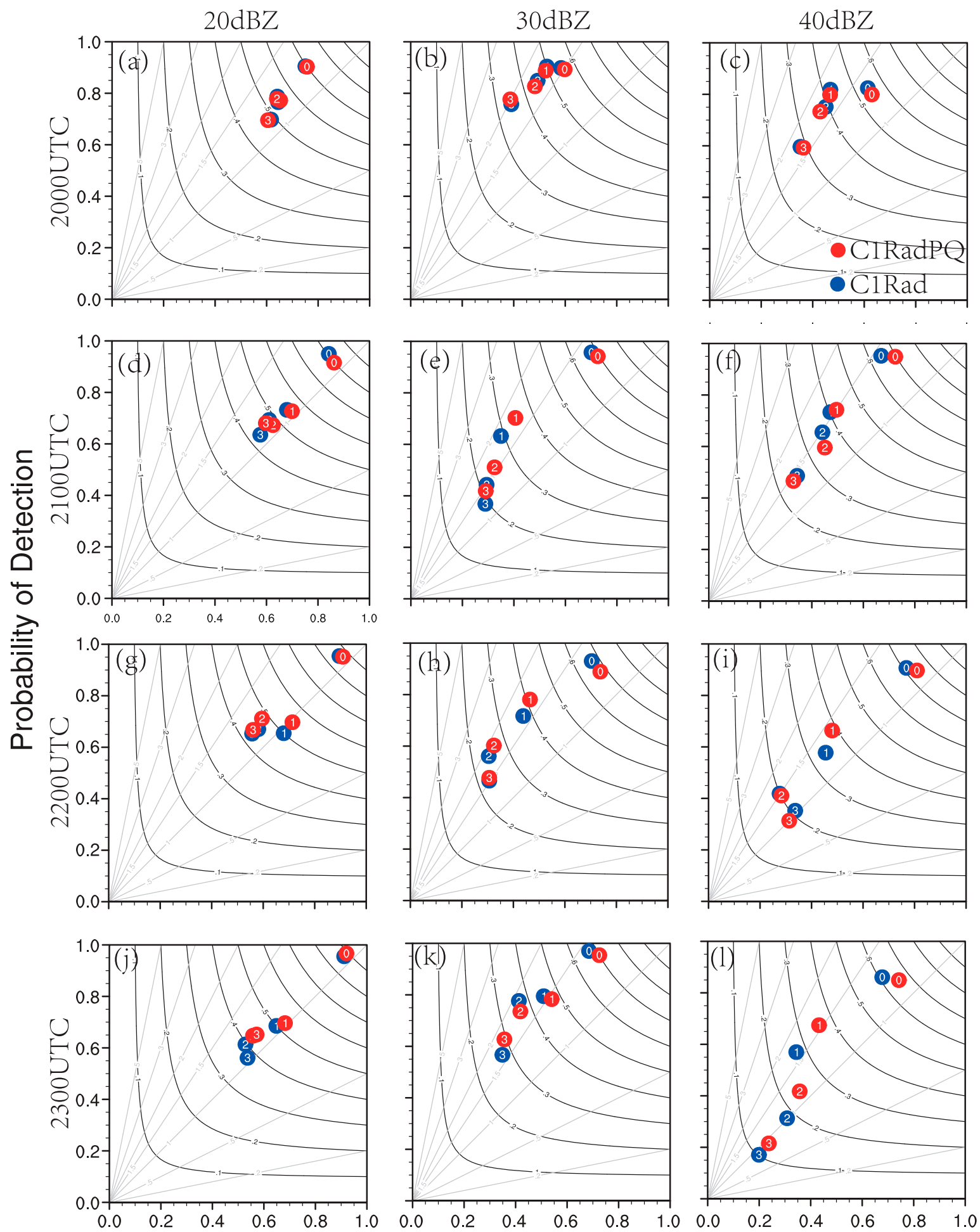

\section{Success Ratio (1 - FAR)}

FIG. 9. Performance diagrams for 0-3-h forecasts of composite reflectivity fields initiated at (a)-(c) 2000 UTC, (d)-(f) 2100 UTC, (g)(i) 2200 UTC, and (j)-(l) 2300 UTC 16 May 2017: shown are the results for the (left) 20-, (middle) 30-, and (right) 40-dBZ thresholds. The lower-left corner represents no forecast skill and, similarly, the upper-right corner indicates perfect skill. Black curves represent the critical success index (CSI), and the diagonal gray lines the frequency bias. The blue and red dots show the results for C1Rad and C1RadPQ, respectively. The number inside each dot represents the length of the forecast (" 0 " is for 0 -h forecast or analysis, " 1 " is for 1 -h forecast ... etc). 

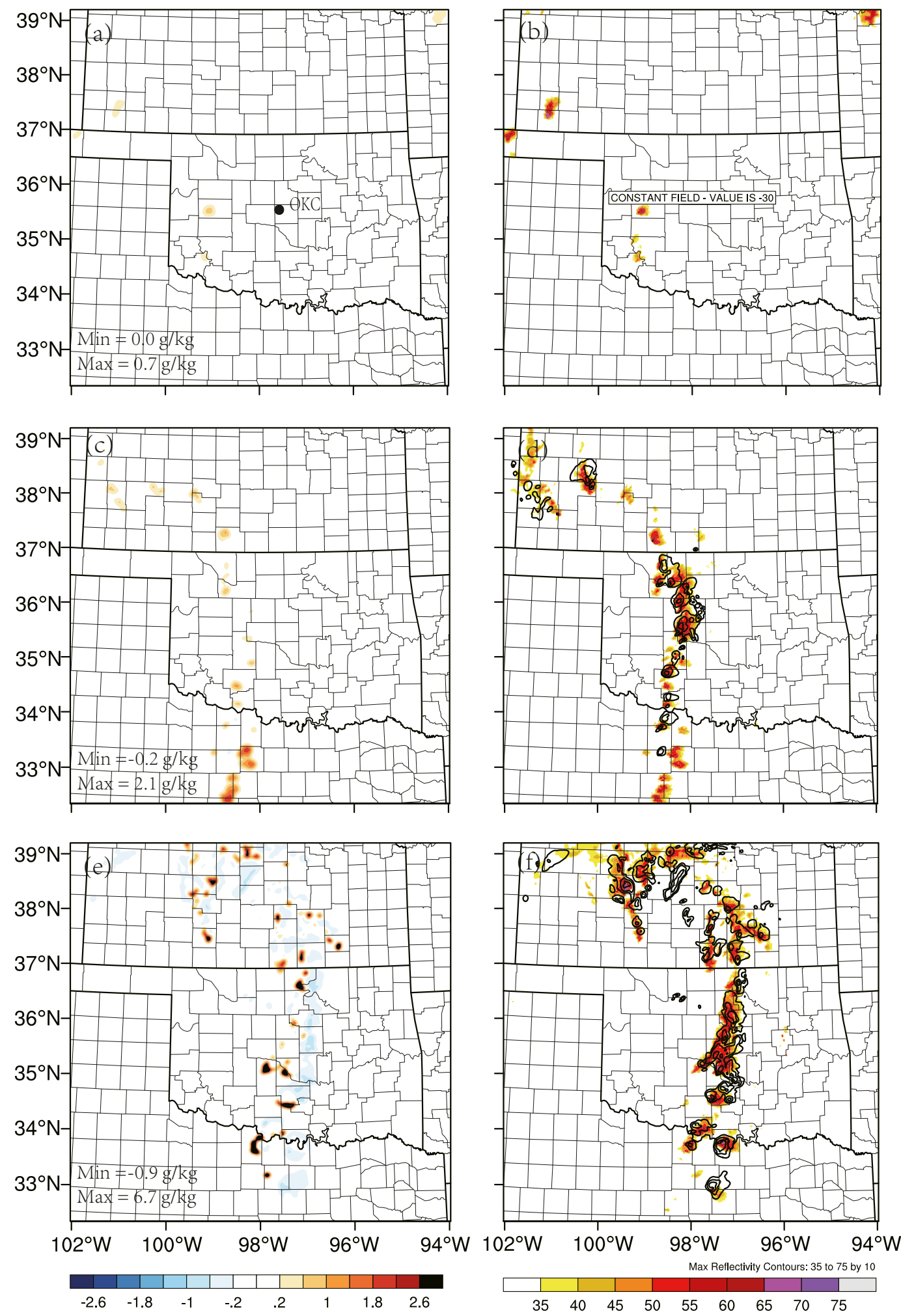

FIG. 10. As in Fig. 4, but for 24 May 2011. In (a), the label "OKC" marks the location of the Oklahoma City metro area. 
the assimilation period, the background fields are derived from the analysis products of NCEP's Global Forecast System (GFS), so no hydrometeors or radar echoes are present in the simulation domain. After the first analysis, weak positive $q_{v}$ increments appear in west Oklahoma and southwest Kansas (Fig. 10a), which associate well with the reflectivity observations (Fig. 10b). The maximum increment for $q_{v}$ after the assimilation is $0.7 \mathrm{~g} \mathrm{~kg}^{-1}$. With the subsequent assimilation cycles, at 2100 UTC, multiple storm cells begin to develop in central Oklahoma and ultimately merge into a quasilinear convective system (QLCS) in parts of Kansas, Oklahoma, and Texas. The $q_{v}$ increments match these storm cells reasonably well (Fig. 10c) with the maximum increment $\left(2.1 \mathrm{~g} \mathrm{~kg}^{-1}\right)$ located near north Texas where multiple storm cells are seen in the radar observations, but missed in the model background. At 2300 UTC, the simulated radar echoes collocate more consistently with radar observations (Fig. 10f). Similar to Fierro et al. (2016), the $q_{v}$ increments are confined to small areas where strong convective cores are located with a maximum value of $6.7 \mathrm{~g} \mathrm{~kg}^{-1}$.

The analyzed reflectivity fields at the end of the 4-h data assimilation period for C2Rad (Fig. 11b) and C2RadPQ (Fig. 11c) show that the assimilation of pseudo- $q_{v}$ produces stronger supercells based on the reflectivity patterns, especially near the southern boundary of the domain (Fig. 11a). Similar to the previous case study, the forecast initialized at 2300 UTC is described and shown as an example. At the analysis time, a well-defined QLCS about $650 \mathrm{~km}$ long and $400 \mathrm{~km}$ wide is produced in the domain and slowly moves northeastward. To facilitate the discussion, the QLCS was divided into 5 regions labeled from $\mathrm{A}$ to $\mathrm{E}$ (Fig. 11a). In general, both C2Rad and C2RadPQ produce reasonable $0-3$-h forecasts, especially for region $\mathrm{C}$ which contains the most intense portion of the QLCS (Fig. 11). In C2Rad, the storms in region D gradually weaken over the $0-3-h$ forecast (Figs. 11e,h,k). The storms in region $\mathrm{D}$, however, strengthen in the C2RadPQ (Figs. 11f,i,1), and remain in better agreement with the observations despite admittedly being weakerthan-observed (Figs. 11e,g,j). The storms in regions A and $\mathrm{B}$ are generally well forecasted in both experiments in contrast to those in region $\mathrm{E}$ that neither experiment simulated well.

Similar to the first case study, the impact of the pseudo$q_{v}$ assimilation is limited during the first forecast initialized at 2000 UTC as evidenced by similar composite reflectivity/UH tracks in both experiments (Figs. 12b,c), generally not agreeing with observations and SPC reports (Fig. 12a). For the forecast initialized at 2100 UTC, the assimilation of pseudo- $q_{v}$ improves the representation of reflectivity tracks in central Oklahoma by producing stronger echoes, which in turn corroborate well with the SPC's tornado and hail reports especially near central Oklahoma (Figs. 12d,e,f). When the forecast is initialized at 2200 UTC, the forecast reflectivity tracks for two storms near the Texas and Oklahoma border match the severe weather report reasonably well for C1RadPQ (Fig. 12i). In comparison, C1Rad failed to forecast these two storm tracks (Fig. 12h). For the last forecast initialized at 2300 UTC, the storm tracks in this same area are gradually improved in C1RadPQ (Fig. 12l). For the QLCS in central and southeast Kansas, the performance of both experiments is similar. The $2-5-\mathrm{km} \mathrm{UH}$ tracks for the same four forecast times further highlight the positive (and confined) impact of the pseudo- $q_{v}$ assimilation through more consistent placement with respect to the SPC reports (Fig. 13).

The ETS values with C2RadPQ for all four $0-3-\mathrm{h}$ forecasts remain generally superior relative to $\mathrm{C} 2 \mathrm{Rad}$ regardless of the reflectivity threshold value chosen (Fig. 14). Overall, the ETS decrease more rapidly when the reflectivity threshold is increased from 20 to $40 \mathrm{dBZ}$. The relative improvement of ETS for C2RadPQ is more obvious at $20 \mathrm{dBZ}$ (Fig. 14a). Performance diagrams indicate that at all reflectivity thresholds, the CSI and POD are superior in C2RadPQ for all 0-3-h forecasts (Fig. 15). At larger reflectivity thresholds (30 and $40 \mathrm{dBZ}$ ), however, the biases do show a noteworthy (but reasonable) increase, especially for the forecasts initiated at 2200 and 2300 UTC (Figs. 15h,i,k,l). The bias values are larger because of increased storm coverage with time coupled with an overestimate of hydrometeor content (and likely, rainfall) by the microphysics (Fierro et al. 2015).

\section{Summary and conclusions}

While water vapor $\left(q_{v}\right)$ is a critical component of convective systems, high spatiotemporal observations of this field are lacking. Over the past several years, several pathways have been explored to derive pseudo- $q_{v}$ data. These include deriving pseudo- $q_{v}$ from radar reflectivity (H. Wang et al. 2013a; Gao et al. 2018), lightning data (Fierro et al. 2016), and differential reflectivity (Carlin et al. 2017). These derived data were then assimilated into NWP models at convection-allowing scales $(d x \leq 3-4 \mathrm{~km})$. In this study, an alternative approach/algorithm to derive pseudo- $q_{v}$ observations from radar reflectivity data is proposed and tested systematically for two high-impact weather events.

The first step of this new algorithm is to identify areas of deep moist convection using the vertically integrated liquid (VIL) calculated from 3D reflectivity observations. If the calculated VIL values exceeds a given, fixed 

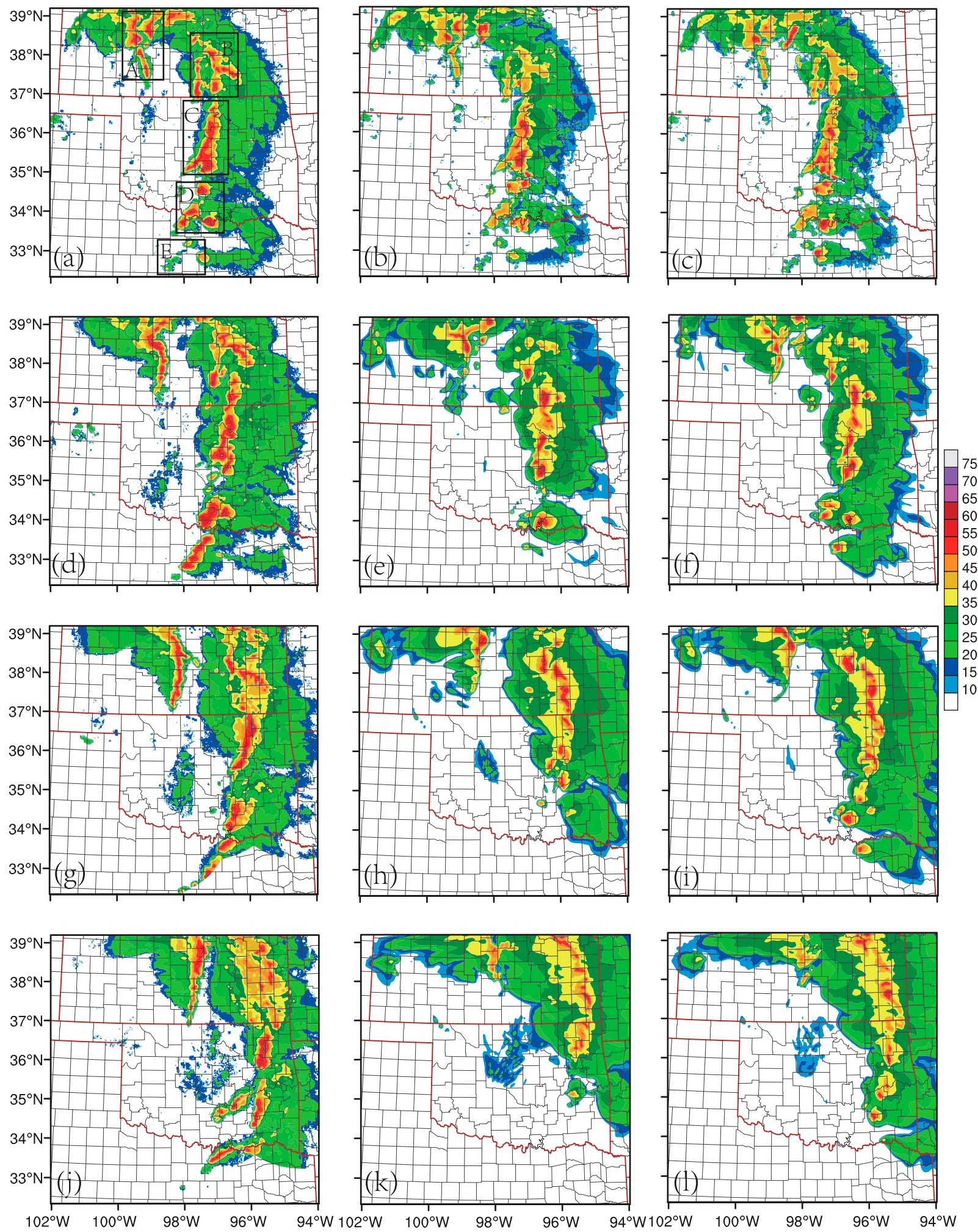

FIG. 11. As in Fig. 5, but for 24 May 2011. 

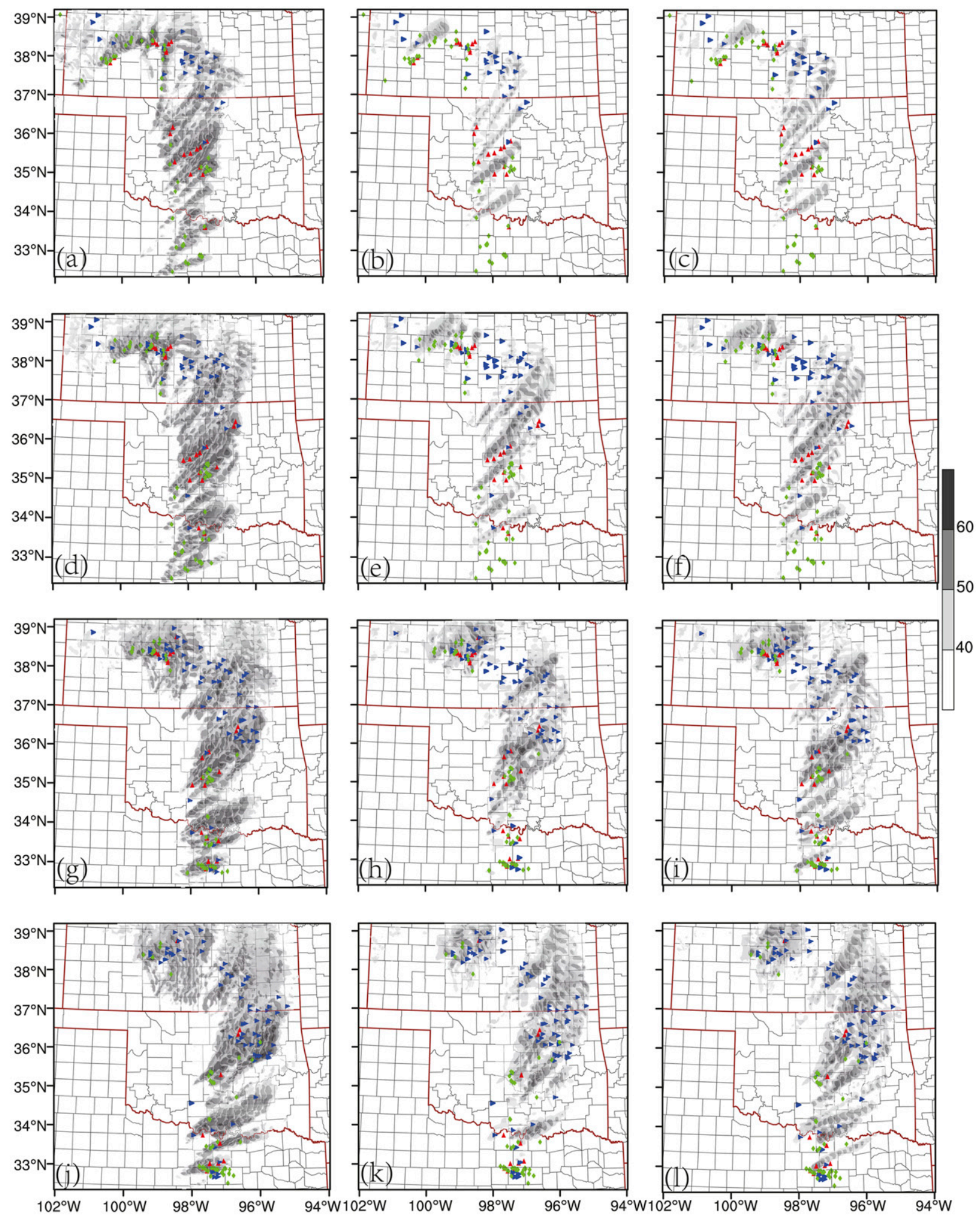

FIG. 12. As in Fig. 6, but for 24 May 2011. 

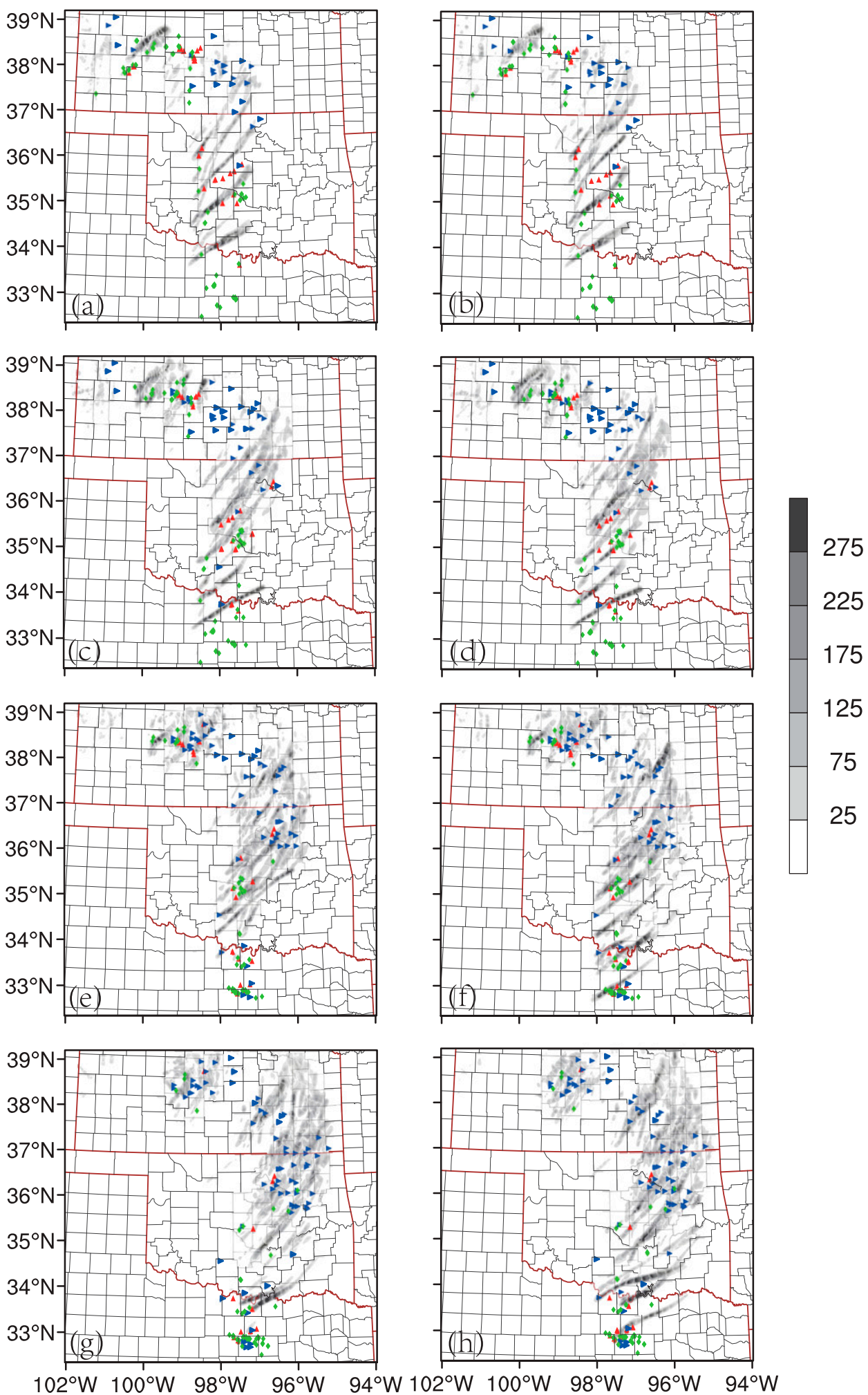

FIG. 13. As in Fig. 7, but for 24 May 2011. 
ETS(20dBZ)
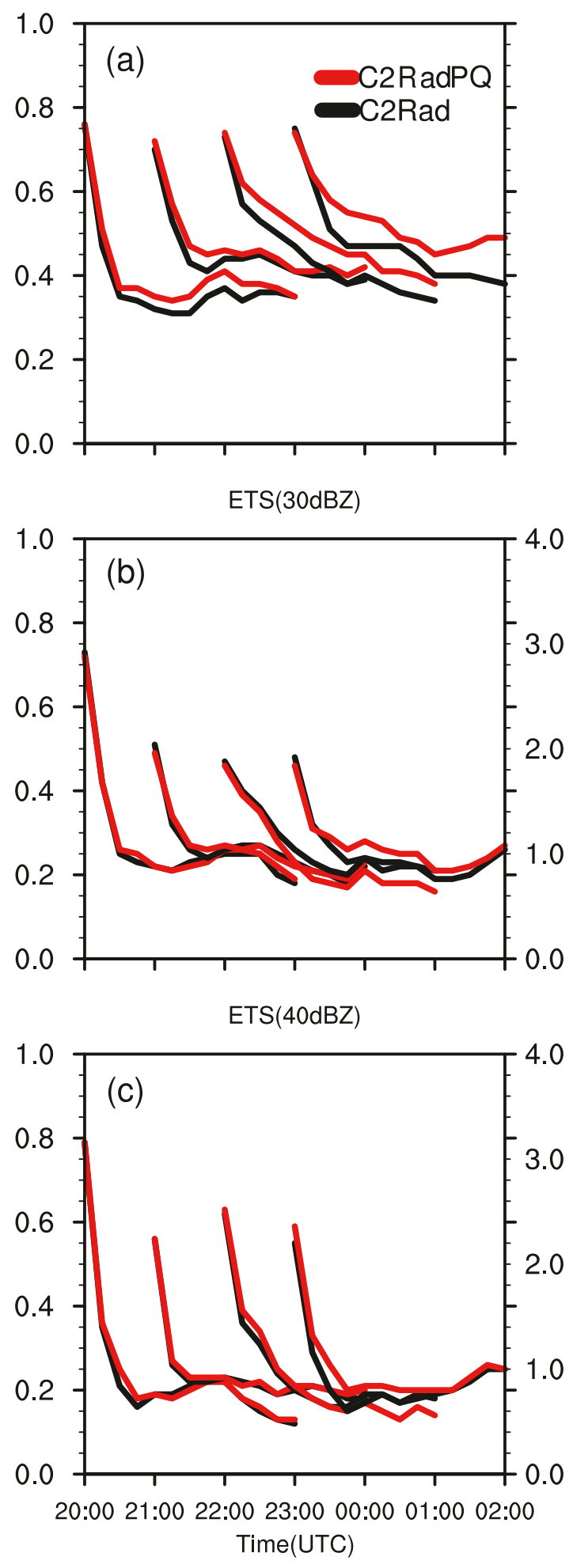

FIG. 14. As in Fig. 8, but for 24 May 2011. threshold provided the existence of reflectivity values meeting a fixed criterion ( $35 \mathrm{dBZ})$, the column is classified as convective. Based on this hypothesis, pseudo- $q_{v}$ is calculated by assuming saturation at these locations (i.e., saturation with respect to liquid substance). If the calculated VIL exceeds the aforementioned fixed threshold in any given area based on model background reflectivity, but without support from observations, these are categorized as spurious convection. In this case, the algorithm reduces the background relative humidity at these locations to suppress (or at least weaken) convection. The next and final step is to assimilate the derived pseudo$q_{v}$ observations into the model together with radar radial velocity and reflectivity in a 3DVAR framework with 15-min data assimilation cycles over a 4-h data assimilation period, and launch 3-h forecasts every hour.

The proposed new approach has been examined for two tornadic severe weather events, namely the 16 May 2017 tornadic supercells in Texas and Oklahoma and the 24 May 2011 tornadic outbreak in Oklahoma. In both cases, two experiments are performed, one with and one without the assimilation of pseudo- $q_{v}$ observations. The analyses and forecasts of these two severe weather events are qualitatively and quantitatively improved in both cases when the pseudo- $q_{v}$ observations are assimilated, including: obtaining more consistent analyses of moisture and better analyses of precipitation; reductions of spurious storm cells; and more realistic prediction of reflectivity patterns and updraft helicity tracks which better match the observed tornado damage tracks.

The performance of assimilating VIL-derived pseudowater vapor observations, however, is only tested for two single cases which occurred over the same geographical area (U.S. Great Plains) and during the same season (spring). It is possible that heavy precipitation areas actually associated with downdrafts (that are also potentially unsaturated) having large values of VIL, particularly if they are collapsing. Alternatively, it is also possible that a storm containing a very strong updraft might actually produce locally smaller values of VIL. In the future, it would be worth looking into alternative methods to derive more accurate estimations of the VIL threshold for different place and/or seasons. Additionally, more case studies are needed to improve the performance of the new method. Future work is underway to combine the VIL approach with other existing or new methods in an attempt to more accurately identify regions characterized by deep moist convection.

As discussed earlier, several methods for deriving and assimilating pseudo- $q_{v}$ observations into convectivescale NWP have been investigated in previous studies. Among them, the $Z_{\mathrm{DR}}$ column algorithm appears to offer promise. It has been found challenging, however, 

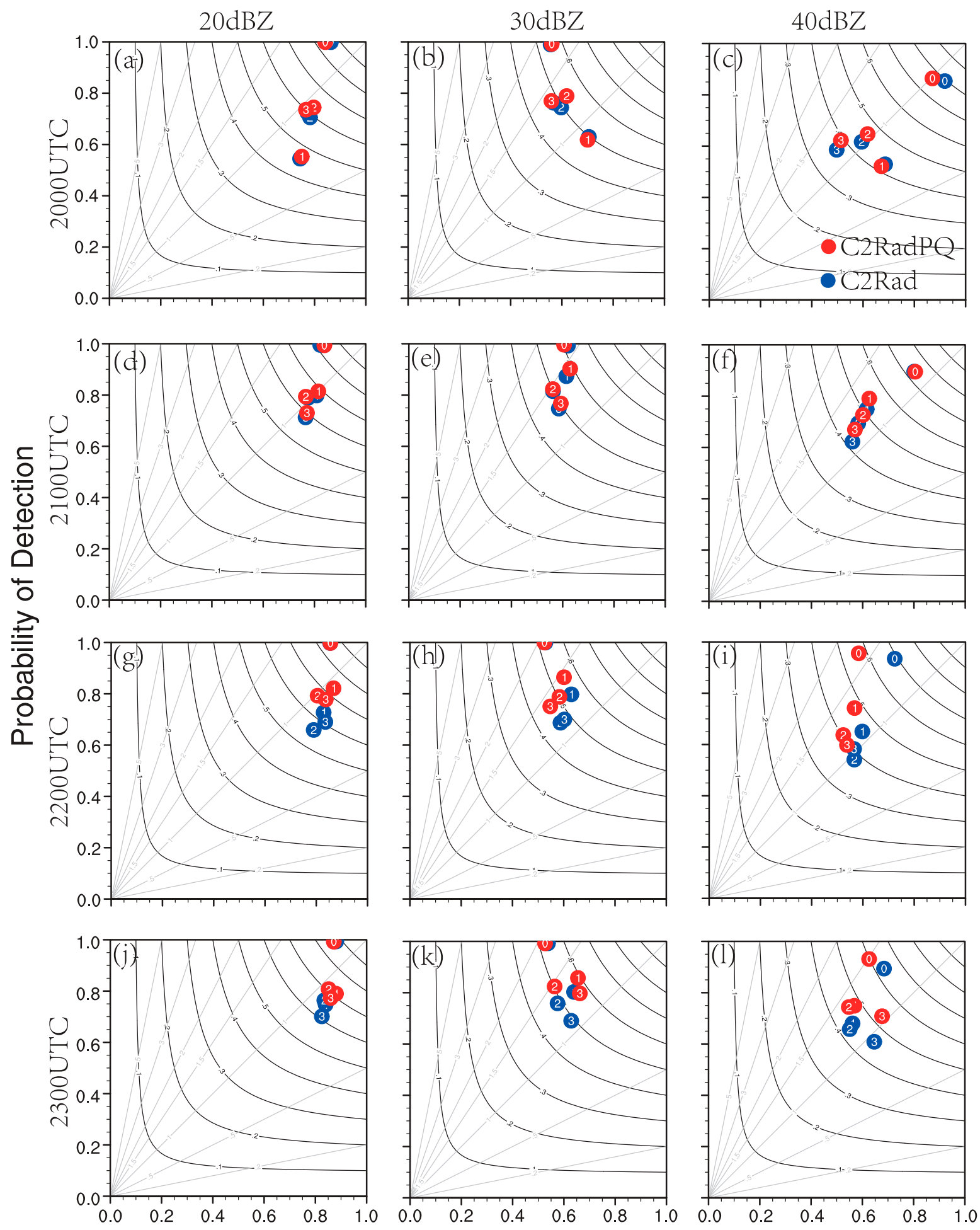

Success Ratio (1 - FAR)

FIG. 15. As in Fig. 9, but for 24 May 2011. 
to mosaic $Z_{\mathrm{DR}}$ column data from multiple radars. Other investigators also have proposed pathways to assimilate pseudo- $q_{v}$ observations derived from total lightning data measured by ground-based networks (ENTLN) or spaceborne instruments (GLM). With the advent of the recent successful launches of the GOES-16 (November 2016) and GOES-17 (March 2018) satellites, more data with uniform, high spatiotemporal coverage over large geographical areas are becoming available. This warrants the development and testing of several types of proof-of-concept data assimilation approaches spanning various frameworks (3DVAR, 4DVAR, EnKF, or hybrid) to better understand how the information they contain could benefit NWP forecast over a wide range of scales. It will be particularly informative to perform case studies with these three types of available data. In this way, we may better understand which method is more effective and if the combined use of these datasets can result in improved convective scale NWP.

Acknowledgments. This work was primarily supported by the Key Program for International S\&T Cooperation Projects of China (Grant 2016YFE0109400), National Natural Science Foundation of China (Grant 41620104009), and U.S. National Science Foundation AGS-1341878. Funding was also provided by NOAA/Office of Oceanic and Atmospheric Research under NOAA-University of Oklahoma Cooperative Agreement NA11OAR4320072, U.S. Department of Commerce, and by Grant NOAANWS-NWSPO-2018-2005317. Computing resources were provided by the University of Oklahoma (OU) Supercomputing Center for Education and Research (OSCER).

\section{REFERENCES}

Aksoy, A., D. C. Dowell, and C. Snyder, 2009: A multicase comparative assessment of the ensemble Kalman filter for assimilation of radar observations. Part I: Storm-scale analyses. Mon. Wea. Rev., 137, 1805-1824, https://doi.org/10.1175/ 2008MWR2691.1.

Albers, S. C., J. A. McGinley, D. L. Birkenheuer, and J. R. Smart, 1996: The Local Analysis and Prediction System (LAPS): Analyses of clouds, precipitation, and temperature. Wea. Forecasting, 11, 273-287, https://doi.org/10.1175/1520-0434(1996) $011<0273$ :TLAAPS $>2.0$. CO;2.

Carlin, J. T., J. Gao, J. C. Snyder, and A. V. Ryzhkov, 2017: Assimilation of $Z_{D R}$ columns for improving the spinup and forecast of convective storms in storm-scale models: Proof-ofconcept experiments. Mon. Wea. Rev., 145, 5033-5057, https:// doi.org/10.1175/MWR-D-17-0103.1.

Caumont, O., V. Ducrocq, E. Wattrelot, G. Jaubert, and S. PradierVabre, 2010: 1D+3DVar assimilation of radar reflectivity data: A proof of concept. Tellus, 62A, 173-187, https://doi.org/ 10.1111/j.1600-0870.2009.00430.x.

Clark, A. J., W. A. Gallus, and M. L. Weisman, 2010: Neighborhood-based verification of precipitation forecasts from convection-allowing NCAR WRF model simulations and the operational NAM. Wea. Forecasting, 25, 1495-1509, https:// doi.org/10.1175/2010WAF2222404.1.

Doviak, R. J., and D. S. Zrnić, 1993: Doppler Radar and Weather Observations. 2nd ed. Academic Press, 562 pp.

Dowell, D. C., L. J. Wicker, and C. Snyder, 2011: Ensemble Kalman filter assimilation of radar obervations of the 8 May 2003 Oklahoma City supercell: Influences of reflectivity observations on storm-scale analyses. Mon. Wea. Rev., 139, 272-294, https://doi.org/10.1175/2010MWR3438.1.

Ducrocq, V., J. Lapore, J. Redelsperger, and F. Orain, 2000: Initialization of a fine-scale model for convective-system prediction: A case study. Quart. J. Roy. Meteor. Soc., 126, 3041-3065, https:// doi.org/10.1002/qj.49712657004.

Dudhia, J., 1989: Numerical study of convection observed during the Winter Monsoon Experiment using a mesoscale two-dimensional model. J. Atmos. Sci., 46, 3077-3107, https://doi.org/10.1175/15200469(1989)046<3077:NSOCOD>2.0.CO;2.

Fierro, A. O., E. R. Mansell, C. L. Ziegler, and D. R. MacGorman, 2012: Application of a lightning data assimilation technique in the WRF-ARW model at cloud-resolving scales for the tornado outbreak of 24 May 2011. Mon. Wea. Rev., 140, 26092627, https://doi.org/10.1175/MWR-D-11-00299.1.

_ A. J. Clark, E. R. Mansell, D. R. MacGorman, S. R. Dembek, and C. L. Ziegler, 2015: Impact of storm-scale lightning data assimilation on WRF-ARW precipitation forecasts during the 2013 warm season over the contiguous United States. Mon. Wea. Rev., 143, 757-777, https://doi.org/10.1175/MWR-D-1400183.1.

, J. Gao, C. L. Ziegler, E. R. Mansell, D. R. MacGorman, and S. R. Dembek, 2014: Evaluation of a cloud-scale lightning data assimilation technique and a 3DVAR method for the analysis and short-term forecast of the 29 June 2012 derecho event. Mon. Wea. Rev., 142, 183-202, https://doi.org/10.1175/MWRD-13-00142.1.

, - - - K. M. Calhoun, E. R. Mansell, and D. R. MacGorman, 2016: Assimilation of flash extent data in the variational framework at convection-allowing scales: Proofof-concept and evaluation for the short-term forecast of the 24 May 2011 tornado outbreak. Mon. Wea. Rev., 144, 43734393, https://doi.org/10.1175/MWR-D-16-0053.1.

Fillion, L., and J. Mahfouf, 2000: Coupling of moist-convective and stratiform precipitation processes for variational data assimilation. Mon. Wea. Rev., 128, 109-124, https://doi.org/10.1175/ 1520-0493(2000)128<0109:COMCAS>2.0.CO;2.

Gao, J. D., and D. J. Stensrud, 2012: Assimilation of reflectivity data in a convective-scale, cycled 3DVAR framework with hydrometeor classification. J. Atmos. Sci., 69, 1054-1065, https://doi.org/10.1175/JAS-D-11-0162.1.

$\longrightarrow$, and — 2014: Some observing system simulation experiments with a hybrid 3DEnVAR system for storm-scale radar data assimilation. Mon. Wea. Rev., 142, 3326-3346, https:// doi.org/10.1175/MWR-D-14-00025.1.

_ - M. Xue, A. Shapiro, and K. K. Droegemeier, 1999: A variational analysis for the retrieval of three-dimensional mesoscale wind fields from two Doppler radars. Mon. Wea. Rev., 127, 2128-2142, https://doi.org/10.1175/1520-0493(1999) $127<2128$ :AVMFTA $>2.0$. CO;2.

,,-- K. Brewster, and K. K. Droegemeier, 2004: A threedimensional data analysis method with recursive filter for Doppler radars. J. Atmos. Oceanic Technol., 21, 457-469, https:// doi.org/10.1175/1520-0426(2004)021<0457:ATVDAM>2.0.CO;2.

, K. Brewster, and M. Xue, 2008: Variation of radio refractivity with respect to moisture and temperature and influence on 
radar ray path. Adv. Atmos. Sci., 25, 1098-1106, https:// doi.org/10.1007/s00376-008-1098-x.

_- and Coauthors, 2013: A real-time weather-adaptive 3DVAR analysis system for severe weather detections and warnings. Wea. Forecasting, 28, 727-745, https://doi.org/10.1175/WAFD-12-00093.1.

— C. H. Fu, D. J. Stensrud, and J. S. Kain, 2016: OSSEs for an ensemble 3DVAR data assimilation system with radar observations of convective storms. J. Atmos. Sci., 73, 2403-2426, https://doi.org/10.1175/JAS-D-15-0311.1.

Gao, S., J. Sun, J. Min, Y. Zhang, and Z. Ying, 2018: A scheme to assimilate "no rain" observations from Doppler radar. Wea. Forecasting, 33, 71-88, https://doi.org/10.1175/WAF-D-170108.1.

Ge, G., J. Gao, and M. Xue, 2013: Impacts of assimilating measurements of different state variables with a simulated supercell storm and three-dimensional variational method. Mon. Wea. Rev., 141, 2759-2777, https://doi.org/10.1175/MWR-D12-00193.1.

Gilmore, M. S., J. M. Straka, and E. N. Rasmussen, 2004: Precipitation and evolution sensitivity in simulated deep convective storms: Comparisons between liquid-only and simple ice and liquid phase microphysics. Mon. Wea. Rev., 132, 1897-1916, https://doi.org/ 10.1175/1520-0493(2004)132<1897:PAESIS > 2.0.CO;2.

Goodman, S. J., and Coauthors, 2013: The GOES-R Geostationary Lightning Mapper(GLM). Atmos. Res., 125-126, 34-49, https://doi.org/10.1016/j.atmosres.2013.01.006.

Greene, D. R., and R. A. Clark, 1972: Vertically integrated liquid water-A new analysis tool. Mon. Wea. Rev., 100, 548-552, https:// doi.org/10.1175/1520-0493(1972)100<0548:VILWNA > 2.3.CO;2.

Haase, G., S. Crewell, C. Simmer, and W. Wergen, 2000: Assimilation of radar data in mesoscale models: Physical initialization and latent heat nudging. Phys. Chem. Earth, Part B Hydrol. Oceans Atmos, 25, 1237-1242, https://doi.org/10.1016/ S1464-1909(00)00186-6.

Hu, M., M. Xue, and K. Brewster, 2006a: 3DVAR and cloud analysis with WSR-88D Level-II data for the prediction of the Fort Worth tornadic thunderstorms. Part I: Cloud analysis and its impact. Mon. Wea. Rev., 134, 675-698, https://doi.org/ 10.1175/MWR3092.1.

,-- J. Gao, and K. Brewster, 2006b: 3DVAR and cloud analysis with WSR-88D Level-II data for the prediction of the Fort Worth tornadic thunderstorms. Part II: Impact of radial velocity analysis via 3DVAR. Mon. Wea. Rev., 134, 699-721, https://doi.org/10.1175/MWR3093.1.

Jones, C. D., and B. Macpherson, 1997: A latent heat nudging scheme for the assimilation of precipitation data into an operational mesoscale model. Meteor. Appl., 4, 269-277, https:// doi.org/10.1017/S1350482797000522.

Klazura, G. E., and D. A. Imy, 1993: A description of the initial set of analysis products available from the NEXRAD WSR-88D system. Bull. Amer. Meteor. Soc., 74, 1293-1312, https://doi.org/ 10.1175/1520-0477(1993)074<1293:ADOTIS>2.0.CO;2.

Kumjian, M. R., 2013: Principles and applications of dualpolarization weather radar. Part I: Description of the polarimetric radar variables. J. Oper. Meteor., 1, 226-242, https:// doi.org/10.15191/nwajom.2013.0119.

Li, W., Y. F. Xie, S. M. Deng, and Q. Wang, 2010: Application of the multigrid method to the two-dimensional Doppler radar radial velocity data assimilation. J. Atmos. Oceanic Technol., 27, 319-332, https://doi.org/10.1175/2009JTECHA1271.1.

Lin, Y.-L., R. D. Farley, and H. D. Orville, 1983: Bulk parameterization of the snow field in a cloud model. J. Climate Appl.
Meteor., 22, 1065-1092, https://doi.org/10.1175/1520-0450(1983) 022<1065:BPOTSF $>2.0$. CO;2.

Lin, Y., P. S. Ray, and K. W. Johnson, 1993: Initialization of a modeled convective storm using Doppler radar-derived fields. Mon. Wea. Rev., 121, 2757-2775, https://doi.org/10.1175/15200493(1993) $121<2757$ :IOAMCS $>2.0$.CO;2.

Lopez, P., and P. Bauer, 2007: "1D + 4DVAR" assimilation of NCEP Stage-IV radar and gauge hourly precipitation data at ECMWF. Mon. Wea. Rev., 135, 2506-2524, https://doi.org/ 10.1175/MWR3409.1.

Macpherson, B., B. J. Wright, W. H. Hand, and A. J. Maycock, 1996: The Impact of MOPS moisture data in the U.K. Meteorological Office mesoscale data assimilation scheme. Mon. Wea. Rev., 124, 1746-1766, https://doi.org/10.1175/15200493(1996)124<1746:TIOMMD>2.0.CO;2.

Marécal, V., and J.-F. Mahfouf, 2002: Four-dimensional variational assimilation of total column water vapor in rainy areas. Mon. Wea. Rev., 130, 43-58, https://doi.org/10.1175/1520-0493(2002) 130<0043:FDVAOT >2.0.CO;2.

$\longrightarrow$, and - 2003: Expericaments on 4DVAR assimilation of rainfall data using an incremental formulation. Quart. J. Roy. Meteor. Soc., 129, 3137-3160, https://doi.org/10.1256/qj.02.120.

Mlawer, E. J., S. J. Taubman, P. D. Brown, M. J. Iacono, and S. A. Clough, 1997: Radiative transfer for inhomogeneous atmospheres: RRTM, a validated correlated-k model for the longwave. J. Geophys. Res., 102, 16663-16682, https://doi.org/ 10.1029/97JD00237.

Purser, R. J., W.-S. Wu, D. F. Parrish, and N. M. Roberts, 2003a: Numerical aspects of the application of recursive filters to variational statistical analysis. Part I: Spatially homogeneous and isotropic Gaussian covariances. Mon. Wea. Rev., 131, 1524-1535, https:// doi.org/10.1175//1520-0493(2003)131<1524:NAOTAO > 2.0.CO;2. ,,,--- and $-2003 \mathrm{~b}$ : Numerical aspects of the application of recursive filters to variational statistical analysis. Part II: Spatially inhomogeneous and anisotropic general covariances. Mon. Wea. Rev., 131, 1536-1548, https://doi.org/ 10.1175//2543.1.

Roebber, P. J., 2009: Visualizing multiple measures of forecast quality. Wea. Forecasting, 24, 601-608, https://doi.org/10.1175/ 2008WAF2222159.1.

Schenkman, A. D., 2012: Exploring tornadogenesis with high resolution simulations initialized with real data. $\mathrm{Ph}$.D. dissertation, University of Oklahoma, $186 \mathrm{pp}$.

_ - X. Ming, A. Shapiro, K. Brewster, and J. Gao, 2011: The analysis and prediction of the 8-9 May 2007 Oklahoma tornadic mesoscale convective system by assimilation WSR-88D and CASA radar data using 3DVAR. Mon. Wea. Rev., 139, 224-246, https://doi.org/10.1175/2010MWR3336.1.

Skamarock,W. C., and Coauthors, 2008: A description of the Advanced Research WRF version 3. NCAR Tech. Note NCAR/ TN-475+STR, 113 pp., https://doi.org/10.5065/D68S4MVH.

Snyder, J. C., A. V. Ryzhkov, M. R. Kumjian, A. P. Khain, and J. Picca, 2015: A $Z_{\mathrm{DR}}$ column detection algorithm to examine convective storm updrafts. Wea. Forecasting, 30, 1819-1844, https://doi.org/10.1175/WAF-D-15-0068.1.

Sokol, Z., and D. Rezacova, 2006: Assimilation of radar reflectivity into the LM COSMO model with a high horizontal resolution. Meteor. Appl., 13, 317-330, https://doi.org/10.1017/ S1350482706002349.

Stensrud, D. J., and J. D. Gao, 2010: Importance of horizontally inhomogeneous environmental initial conditions to ensemble storm-scale radar data assimilation and very short-range forecasts. Mon. Wea. Rev., 138, 1250-1272, https://doi.org/ 10.1175/2009MWR3027.1. 
Storto, A., and F. T. Tveter, 2009: Assimilating humidity pseudoobservations derived from the cloud profiling radar aboard CloudSat in ALADIN 3D-Var. Meteor. Appl., 16, 461-479, https://doi.org/10.1002/met.144.

Sun, J., and N. A. Crook, 1997: Dynamical and microphysical retrieval from Doppler radar observations using a cloud model and its adjoint. Part I: Model development and simulated data experiments. J. Atmos. Sci., 54, 1642-1661, https://doi.org/ 10.1175/1520-0469(1997)054<1642:DAMRFD>2.0.CO;2.

_ and _ 1998: Dynamical and microphysical retrieval from Doppler radar observations using a cloud model and its adjoint. Part II: Retrieval experiments of an observed Florida convective storm. J. Atmos. Sci., 55, 835-852, https://doi.org/ 10.1175/1520-0469(1998)055<0835:DAMRFD>2.0.CO;2.

— 4D-Var. Part II: Comparison with 3D-Var for a squall line over the U.S. Great Plains. Mon. Wea. Rev., 141, 2245-2264, https://doi.org/10.1175/MWR-D-12-00169.1.

Tanamachi, R. L., P. L. Heinselman, and L. J. Wicker, 2015: Impacts of a storm merger on the 24 May 2011 El Reno, Oklahoma, tornadic supercell. Wea. Forecasting, 30, 501-524, https://oi.org/ 10.1175/WAF-D-14-00164.1.

Thompson, G., P. R. Field, R. M. Rasmussen, and W. R. Hall, 2008: Explicit forecasts of winter precipitation using an improved bulk microphysics scheme. Part II: Implementation of a new snow parameterization. Mon. Wea. Rev., 136, 5095-5115, https://doi.org/10.1175/2008MWR2387.1.

Tong, C. C., 2015: Limitations and potential of complex cloud analysis and its improvement for radar reflectivity data assimilation using OSSES. Ph.D. dissertation, University of Oklahoma, $159 \mathrm{pp}$.

Tong, M. J., and M. Xue, 2005: Ensemble Kalman filter assimilation of Doppler radar data with a compressible nonhydrostatic model: OSS experiments. Mon. Wea. Rev., 133, 1789-1807, https://doi.org/10.1175/MWR2898.1.

Wang, H., J. Sun, S. Fan, and X.-Y. Huang, 2013a: Indirect assimilation of radar reflectivity with WRF 3D-Var and its impact on prediction of four summertime convective events. J. Appl. Meteor. Climatol., 52, 889-902, https://doi.org/ 10.1175/JAMC-D-12-0120.1.

,$- \ldots$, X. Zhang, X. Y. Huang, and T. Auligne, 2013b: Radar data assimilation with WRF 4D-Var. Part I: System development and preliminary testing. Mon. Wea. Rev., 141, 2224-2244, https://doi.org/10.1175/MWR-D-12-00168.1.

Wang, X., D. Parrish, D. Kleist, and J. Whitaker, 2013: GSI 3DVarbased ensemble-variational hybrid data assimilation for NCEP global forecast system: Single-resolution experiments. Mon. Wea. Rev., 141, 4098-4117, https://doi.org/10.1175/ MWR-D-12-00141.1.

Wang, Y., and X. Wang, 2017: Direct assimilation of radar reflectivity without tangent linear and adjoint of the nonlinear observation operator in the GSI-based EnVar system: Methodology and experiment with the 8 May 2003 Oklahoma City tornadic supercell. Mon. Wea. Rev., 145, 1447-1471, https:// doi.org/10.1175/MWR-D-16-0231.1.

Wattrelot, E., O. Caumont, and J. F. Mahfouf, 2014: Operational implementation of the 1D+3D-Var assimilation method of radar reflectivity data in the AROME model. Mon. Wea. Rev., 142, 1852-1873, https://doi.org/10.1175/MWR-D-13-00230.1.

Weygandt, S. S., A. Shapiro, and K. K. Droegemeier, 2002: Retrieval of model initial fields from single-doppler observations of a supercell thunderstorm. Part II: Thermodynamic retrieval and numerical prediction. Mon. Wea. Rev., 130, 454-476, https://doi.org/10.1175/1520-0493(2002)130<0454: ROMIFF $>2.0 . \mathrm{CO} ; 2$.

Xiao, Q., and J. Sun, 2007: Multiple-radar data assimilation and short-range quantitative precipitation forecasting of a squall line observed during IHOP_2002. Mon. Wea. Rev., 135, 33813404, https://doi.org/10.1175/MWR3471.1.

Xie, Y., S. E. Koch, J. A. McGinley, S. Albers, P. Bieringer, M. Wolfson, and M. Chan, 2011: A space and time multiscale analysis system: A sequential variational analysis approach. Mon. Wea. Rev., 139, 1224-1240, https://doi.org/10.1175/ 2010MWR3338.1.

Xue, M., and Coauthors, 2001: The Advanced Regional Prediction System (ARPS) - A multi-scale nonhydrostatic atmospheric simulation and prediction tool. Part II: Model physics and applications. Meteor. Atmos. Phys., 76, 143-165, https:// doi.org/10.1007/s007030170027.

, D.-H. Wang, J.-D. Gao, K. Brewster, and K. K. Droegemeier, 2003: The Advanced Regional Prediction System (ARPS), storm-scale numerical weather prediction and data assimilation. Meteor. Atmos. Phys., 82, 139-170, https://doi.org/ 10.1007/s00703-001-0595-6.

Yussouf, N., and D. J. Stensrud, 2010: Impact of phased array radar observation over a short assimilation period: Observing system simulation experiments using ensemble Kalman filter. Mon. Wea. Rev., 138, 517-538, https://doi.org/10.1175/ 2009MWR2925.1.

Zhang, F. Q., C. Snyder, and J. Sun, 2004: Impacts of initial estimate and observation availability on convective-scale data assimilation with an ensemble Kalman filter. Mon. Wea. Rev., 132, 1238-1253, https://doi.org/10.1175/1520-0493(2004) $132<1238$ :IOIEAO $>2.0$. CO 2 .

Zhang, J., 1999: Moisture and diabatic initialization based on radar and satellite observations. Ph.D. dissertation, University of Oklahoma, 194 pp.

- and Y. Qi, 2010: A real-time algorithm for the correction of brightband effects in radar-derived QPE. J. Hydrometeor., 11, 1157-1171, https://doi.org/10.1175/2010JHM1201.1.

—, F. Carr, and K. Brewster, 1998: ADAS cloud analysis. Preprints, 12th Conf. on Numerical Weather Prediction, Phoenix, AZ, Amer. Meteor. Soc., 185-188.

_ , and Coauthors, 2011: National Mosaic and Multi-Sensor QPE (NMQ) System: Description, results, and future plans. Bull. Amer. Meteor. Soc., 92, 1321-1338, https://doi.org/ 10.1175/2011BAMS-D-11-00047.1. 